\title{
Light and dark adaptation of visually perceived eye level controlled by visual pitch
}

\author{
LEONARD MATIN and WENXUN LI \\ Columbia University, New York, New York
}

\begin{abstract}
The pitch of a visual field systematically influences the elevation at which a monocularly viewing subject sets a target so as to appear at visually perceived eye level (VPEL). The deviation of the setting from true eye level averages approximately 0.6 times the angle of pitch while viewing a fully illuminated complexly structured visual field and is only slightly less with one or two pitched-fromvertical lines in a dark field (Matin \& Li, 1994a). The deviation of VPEL from baseline following $20 \mathrm{~min}$ of dark adaptation reaches its full value less than $1 \mathrm{~min}$ after the onset of illumination of the pitched visual field and decays exponentially in darkness following 5 min of exposure to visual pitch, either $30^{\circ}$ topbackward or $20^{\circ}$ topforward. The magnitude of the VPEL deviation measured with the dark-adapted right eye following left-eye exposure to pitch was $85 \%$ of the deviation that followed pitch exposure of the right eye itself. Time constants for VPEL decay to the dark baseline were the same for same-eye and cross-adaptation conditions and averaged about $4 \mathrm{~min}$. The time constants for decay during dark adaptation were somewhat smaller, and the change during dark adaptation extended over a $16 \%$ smaller range following the viewing of the dim two-line pitched-from-vertical stimulus than following the viewing of the complex field. The temporal course of light and dark adaptation of VPEL is virtually identical to the course of light and dark adaptation of the scotopic luminance threshold following exposure to the same luminance. We suggest that, following rod stimulation along particular retinal orientations by portions of the pitched visual field, the storage of the adaptation process resides in the retinogeniculate system and is manifested in the focal system as a change in luminance threshold and in the ambient system as a change in VPEL. The linear model previously developed to account for VPEL, which was based on the interaction of influences from the pitched visual field and extraretinal influences from the body-referenced mechanism, was employed to incorporate the effects of adaptation. Connections between VPEL adaptation and other cases of perceptual adaptation of visual direction are described.
\end{abstract}

The physical elevation of visually perceived eye level (VPEL) changes linearly with the pitch ${ }^{1}$ of an illuminated visual field (Matin \& Fox, 1986, 1989; Matin, Fox, \& Doktorsky, 1987; Matin \& Li, 1989b, 1992b, 1992c, 1994a, 1994b, in press; Matin, Li, \& Doktorsky, 1988; Stoper \& Cohen, 1989). Employing the normally illuminated and complexly structured pitchroom shown in Figure 1a, average VPEL values for different groups of 8 subjects in two separate experiments deviated from true eye level by 0.61 and 0.63 times the angle of visual pitch over pitch ranges of $65^{\circ}$ and $50^{\circ}$, respectively; one of the experiments involved monocular viewing, and the second involved binocular viewing. The slope of each subject's VPEL-versus-pitch function was linear, with individual slopes that ranged from +0.44 to +0.84 . These individual slopes have demonstrated a great deal of longterm stability, with changes through as much as 7 years

The authors were supported by Grant AFOSR 91-0146, EY05929 from NEI, NIH and Grant BNS 8617059 from the Sensory Physiology and Perception Program of NSF. An abbreviated report of this work was presented at a meeting of the Association for Research in Vision and Ophthalmology (Matin \& Li, 1992a). Address correspondence to L. Matin, Department of Psychology, Columbia University, New York, NY 10027. generally not exceeding amounts that might be expected from session-to-session variability. Deviations of VPEL settings from true eye level are largest at the extreme pitch values examined (Figure 1b), and for individual subjects have reached as much as $40^{\circ}$ below true eye level at $40^{\circ}$ topbackward pitch, a value at which the target employed for setting VPEL is perceived as being at eye level when it is $0.75 \mathrm{~m}$ below true eye level.

The influence of visual pitch on VPEL is only slightly less when the visual field contains only two dim vertical lines $(88 \%)$ or one vertical line $(82 \%)$ in darkness than when it is complexly structured and normally illuminated (Matin et al., 1987; Matin \& Li, 1989a, 1989b, 1990, 1991a, 199lb, 1991c, 1994a, 1994b, in press; Li \& Matin, 1990, 1991a, 1991b); slopes of the VPEL-versus-pitch functions for $63.1^{\circ}$ long two-line and one-line stimuli averaged +0.56 and +0.52 , respectively, as compared with +0.63 for the fully illuminated room. The slope of the VPEL-versus-pitch function increases exponentially with line length for the one-line stimulus (space constant ranged from $10.1^{\circ}$ to $15.1^{\circ}$ in separate experiments; Li \& Matin, 1991b; Matin \& Li, 1994b). Summation of the influences on VPEL for two lines horizontally separated by $50.3^{\circ}$ is slightly greater than for two coextensive line segments (Matin \& Li, 1989a, 


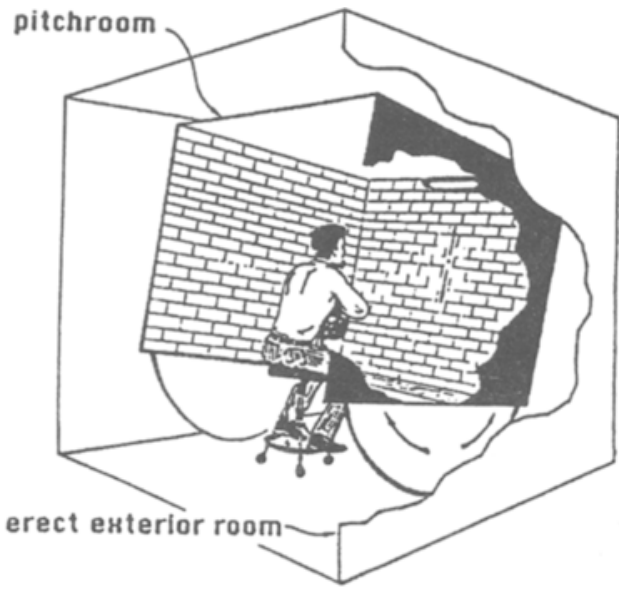

(a)

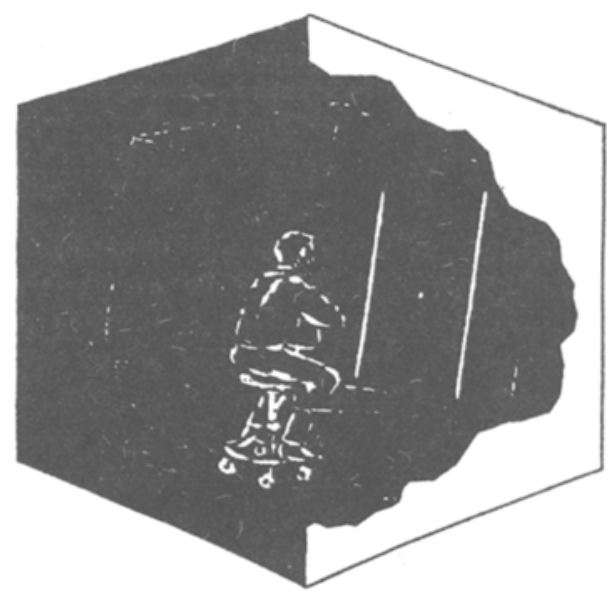

(b)

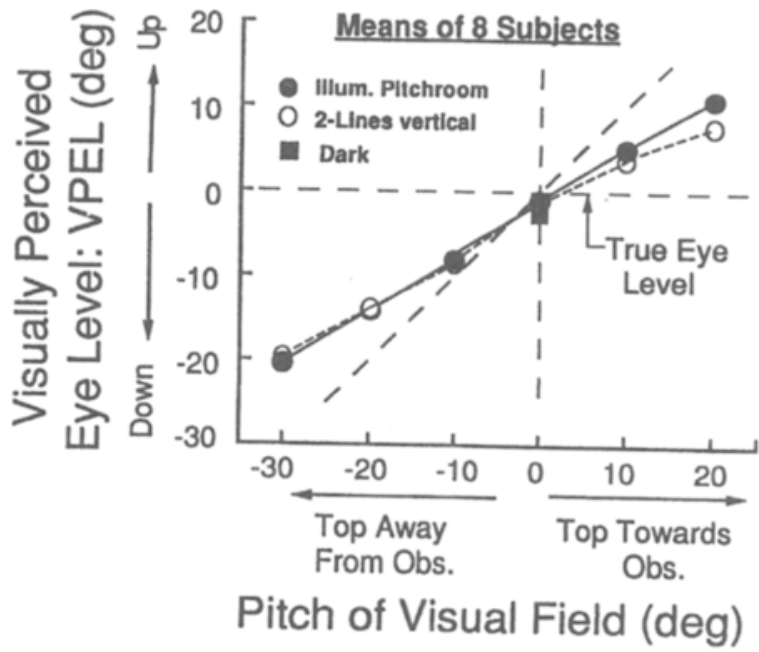

(c)

Figure 1. (a) The pitchroom shown pitched topbackward. The shelf shown on the front wall near knee level was present in the experiments of Figure 1b, but was removed in the present experiments. The arrows on the interior front wall represent the direction in which the subject adjusted the laser target (dot) to appear at the VPEL. A black cloth (shown draped over the subject's knees) was draped over the subject's shoulders and hung between the chinrest and the shelf extending along the bottom of the interior frontal wall in order to hide the exterior floor and the subject's own body. Ilumination was provided by the fluorescent lamp shown at the top of the interior front wall; a shield prevented its direct viewing. (b) The two-line pitched-from-vertical stimulus and projection of beam used for VPEL setting is shown in the otherwise dark pitchroom. (c) Mean VPEL values in the illuminated pitchroom (filled circles), in total darkness (filled square), and in the pitchroom while viewing the two-line pitched-from-vertical stimulus in otherwise total darkness (open circles). Shown are the average results for 8 subjects at six pitches and in total darkness.

1991 a 1994b). Increase in horizontal eccentricity of the lines from $1.25^{\circ}$ to $35^{\circ}$ increases the influence of pitch threefold, but change in the height of the line within the visual field only changes the bias of the VPEL-versuspitch function by a small amount, without any influence on the slope (Li \& Matin, 1990). Changing the pitch of a plane containing only horizontal lines has minimal influence (Matin \& Li, 1989b, 1992b, 1992c, 1994a).

Observers in total darkness are typically able to set a target to VPEL with a precision of less than $1^{\circ}$ and an accuracy that deviates by no more than $5^{\circ}$ from true eye level (Hoppeler, 1913; Li \& Matin, 1990; MacDougall,
1903; Matin \& Fox, 1986, 1989; Matin \& Li, 1989a, 1989b, 1990, 1991b; Matin et al., 1988; Matin et al., 1982; Sharp, 1934; Stoper \& Cohen, 1986, 1989). For VPEL settings in darkness to be other than randomly oriented, the controlling mechanism must make use of some combination of the neural signals regarding three sorts of information: extraretinal information about head orientation relative to gravity (EHOI), extraretinal eye position information relative to the head (EEPI), and information regarding retinal image position of the target used to set VPEL (RI). We have referred to this combination as the body-referenced mechanism. 
Since the slope of the VPEL-versus-pitch function is less than 1.0, the deviation of VPEL from true eye level is less than the angle of the pitched visual field itself. For this to be so, it is very likely that the influence of the visual field is combined with the body-referenced mechanism that functions in darkness. Both the variation of VPEL with visual pitch and the relation of VPEL in the dark to its value in the illuminated pitchroom are well represented by expressing VPEL as a linear weighted combination of influences from the visual field and the body-referenced mechanism (Matin \& Fox, 1989; Matin \& $\mathrm{Li}, 1992 \mathrm{~b}, 1992 \mathrm{c})$ :

$$
\mathrm{VPEL}=k_{v}\left(V_{s}+V_{o}\right)+k_{b}\left(B_{s}+B_{o}\right) .
$$

$V_{s}$ and $B_{S}$ represent the influences on VPEL due to stimulus inputs to the visual system (angular direction normal to the pitched visual field) and to the body-referenced mechanism (angular direction normal to the direction of gravity), respectively, $V_{O}$ and $B_{O}$ are biasing constants characteristic of the individual observer related to visual pitch and the body-referenced mechanism, respectively, and $k_{v}$ and $k_{b}$ are the relative weights of the two influences, with $k_{v}+k_{b}=1$.

In one of the earlier reports (Matin \& Fox, 1989, footnote, p. 324), an asymmetry was noted in the time course with which VPEL reached stable values in the illuminated pitchroom and in darkness. Following complete extinction of the illumination in the pitched room, the VPEL values in complete darkness did not stabilize for some minutes; however, when the pitchroom was reilluminated, VPEL was stable from the first measurements. In the present report we describe quantitative measurements of this temporal asymmetry in adaptation of VPEL for both the pitchroom and the two-line pitchedfrom-vertical stimulus.

\section{METHOD}

Three experiments were carried out to measure the temporal characteristics of the changes in VPEL. In Experiments 1 and 2, VPEL was repeatedly measured with monocular viewing during cycles of light and dark; the visual field in the light phase consisted of an illuminated pitched visual field (the "pitchroom"; Figure la). The rectangular structure of the pitchroom, whose dimensions were $5 \mathrm{ft}$ wide $\times 6 \mathrm{ft}$ long $\times 5 \mathrm{ft}$ high, was mounted on a curved rocker base ( $26.5 \mathrm{in}$. high) that rested on the floor of the exterior room (for further detail, see Matin \& Fox, 1989). In Experiment 3 , the visual field was a two-line pitched-from-vertical stimulus (Figure 1b). The two-line stimulus was made of two strips of luminescent tape that were attached to two parallel arms of a rectangular frame that was attached to the wall of the pitchroom facing the subject; the strips were symmetrically placed relative to the midline of the subject's right eye. Each strip subtended $63.9^{\circ}$ in length and $4.8^{\prime}$ of arc in width at eye level when the pitchroom wall facing the subject was erect; the horizontal separation between the two strips at true eye level was $50.3^{\circ}$ (for further detail regarding the two-line stimulus, see Matin \& Li, 1992c). Visual pitch of the illuminated room or of the two-line stimulus in darkness was controlled by rotating the pitchroom on the semicircular rocker base.
In Experiment 1 ("same-eye condition"), both light adaptation and testing during the light and dark phases were carried out with the right eye of the subject; the left eye was occluded by an eye patch. In Experiment 2 ("cross-adaptation condition"), the left eye was adapted to the pitched visual field during the light phase while the right eye was occluded by the eye patch; VPEL measurements during the dark phase were made on the right eye with the left eye occluded. Experiment 3 ("two-line condition") was run with the design used for Experiment 1, with the exception that during the light phase, the two-line pitched-from-vertical stimulus was viewed in darkness instead of the fully illuminated pitchroom.

In Experiments 1 and 3, light adaptation was with the pitchroom turned either $20^{\circ}$ topforward or $30^{\circ}$ topbackward. In Experiment 2, light adaptation was carried out only with the pitchroom at $30^{\circ}$ topbackward. During all cycles of a given session, light adaptation was applied to the same eye with the same pitch.

During all measurements, the subject was seated as is shown in Figure 1, with head erect and stabilized by the chinrest. The midsagittal plane was perpendicular to the front wall, and the viewing eye was centered horizontally on the front wall at a distance of $1 \mathrm{~m}$, measured along the normal to the wall at the given pitch. In Experiments 1 and 2, the field of view consisted entirely of the front and side walls and the ceiling of the interior of the pitchroom; a black cloth below the subject's chin extended down and in front of his/her body, hiding the floor of the exterior room and the subject's own body. True eye level was measured at the beginning and end of every session by the elevation of the intersection of a horizontal laser beam with the outer canthus. An electronic timer emitting a brief, low-intensity tone burst at 1-min intervals was employed to mark the times when illumination changes and/or VPEL measurements were to take place during each session.

The temporal sequence of experimental measurements during one cycle of light and dark is shown in Figure 2. At the beginning of each session, the pitchroom was erect and all illumination was extinguished. The subject, whose eyes had been closed since entering the room, opened his/her eyes (occluder covered the left eye), and four VPEL measurements were obtained in darkness at approximately 30 -sec intervals. Eyes were closed again and the room was pitched. A second set of four VPEL determinations was made in darkness. In Experiments 1 and 2 the pitchroom was fully illuminated for the next $5 \mathrm{~min}$ of the session, but no measurements were taken (the first period of light adaptation in a session was preceded by too brief a dark period to be useful for the purpose of measuring the course of light adaptation following complete dark adaptation); in Experiment 3 during this period, the subject viewed the two-line stimulus in darkness. The subject was instructed to keep his/her eyes open (right eye viewing in sameeye and two-line conditions, left eye viewing in cross-adaptation condition) and look toward the center of the facing wall, but was not required to fixate any specific location. At the end of the period of light adaptation, all illumination was extinguished and a single VPEL measurement was made in total darkness immediately following each tone burst during the subsequent $20-\mathrm{min}$ period; tone bursts were separated by $1-$ min intervals. Following the 21 st measurement in darkness, the pitchroom was reilluminated (in the same-eye or cross-adaptation conditions), or the twoline stimulus was exposed (in the two-line condition) for $5 \mathrm{~min}$ and the one VPEL measurement/minute routine was continued with the subject viewing the pitchroom set at the orientation it had been prior to the dark period. This sequence was repeated for either two or four cycles in a given session.

In each of the three experiments, measurements were made during a total of four cycles of light and dark in each pitch condition for each subject (two cycles/session); the only exception was for the $30^{\circ}$ topbackward condition on Subject I.P. in Experiment 1, for which there were eight cycles. 


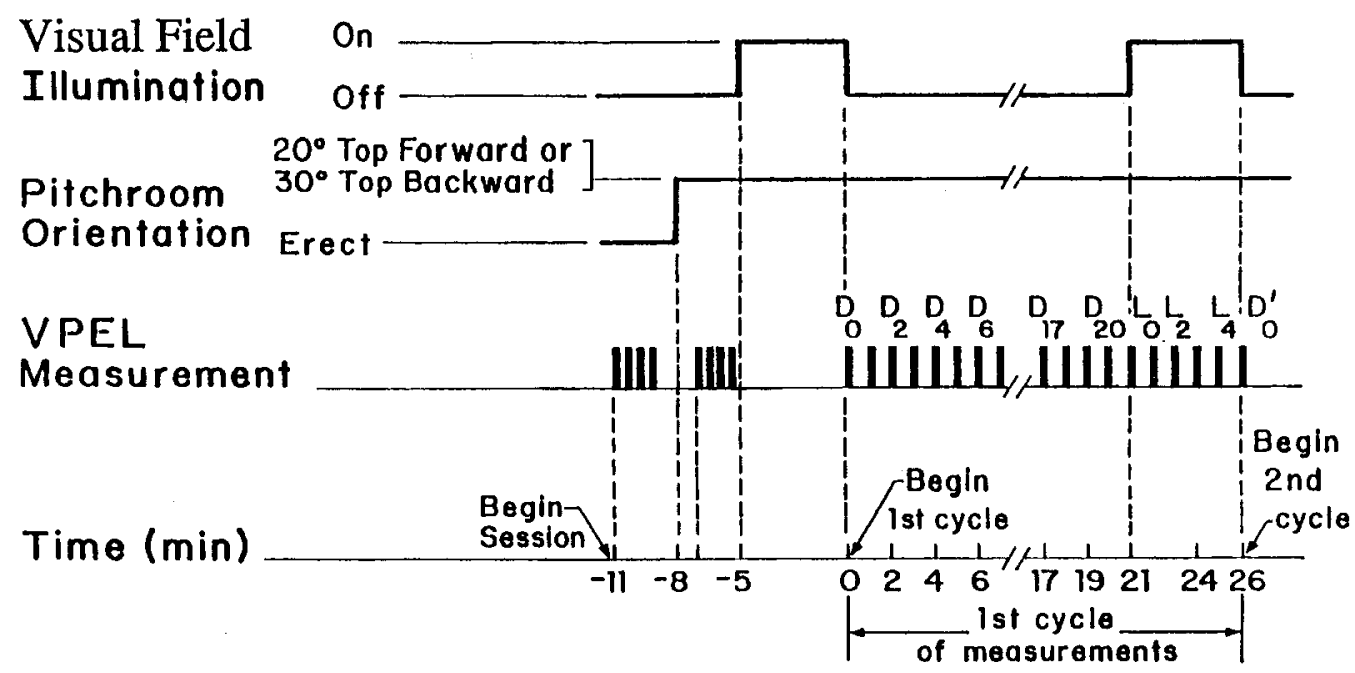

Figure 2. Sequence during an experimental session. The session began with four VPEL (visually perceived eye level) measurements in total darkness in the erect pitchroom; these were followed by four measurements in total darkness with the pitchnoom pitched at the angle at which it was to remain for the remainder of the session. During the subsequent 5 min of exposure to the illuminated pitchroom, no measurements were taken while the subject looked at the center of the interior front wall (monocular viewing: right eye in same-eye experiment, left eye in cross-adaptation experiment). The first measurement in total darkness $\left(D_{0}\right)$ was made during the first minute following extinction of the illumination, and measurements continued at the rate of $1 / \mathrm{min}$ for a total of 21 measurements $\left(D_{0}-D_{20}\right)$ during the 20 min of darkness (all measurements in all experiments on right eye; left eye occluded). The measurements continued during the subsequent 5 min of illumination (measurements $L_{0}-L_{4}$ : right eye in same-eye and two-line experiments; left eye in cross-adaptation experiment). These completed the first cycle. Subsequent cycles repeated the sequence during the first cycle.

Each VPEL measurement was made by having the subject set a $20^{\prime}$ of arc circular red target, projected on the interior wall of the pitchroom facing the subject, to appear at eye level. The subject was initially inst ructed with regard to the criterion to be employed in setting the projected laser target to appear at eye level. This was described to the subject as a setting in which the target would appear to terminate a horizontal line of visual direction - that is, perpendicular to the direction of gravity. The target was derived from a horizontal beam from an attenuated $0.5-\mathrm{mW}$ He-Ne laser outside of the pitchroom behind the subject. The vertical elevation of the target was controlled by the experimenter, who raised or lowered the laser by means of a rack and pinion arrangement mounted on the vertical member of a relay rack to the subject's instruction. A method of adjustment with hunting was employed. The experimenter followed each subject's instructions with a change in laser elevation of variable magnitude until the target was reported to appear at eye level; the subject was instructed to close his/her eyes between settings. Each VPEL value was the average of the settings in four such trials.

The same 6 subjects were employed in the main determinations of Experiments 1 and 2, with only slight variations in the above procedure. Four of the 6 had participated in previous experiments with the pitchroom (W.L., L.M., I.P., and G.V.); for these 4, all work was completed with the $30^{\circ}$ topbackward pitch before beginning work with the $20^{\circ}$ topforward pitch. For the other 2 subjects (C.Z., S.W.), conditions with the two pitchroom orientations were counterbalanced in ABBA order. Two of the subjects were the authors; 2 were undergraduate assistants (I.P., G.V.), and the other 2 (C.Z., S.W.) were individuals who responded to a posted advertisement and were paid an hourly rate. In Experiment 3, 4 subjects were employed; 3 of these had been subjects in Experiments 1 and 2 (W.L., C.Z., and L.M.).
The illumination on the wall facing the subject in Experiments 1 and 2 was derived from the 18-in.-long fluorescent lamp (LOA F15T8CW) located at the top of the wall facing the subject and powered by the $110 \mathrm{vac}$ mains (Figure la). A shield, whose outside surface was covered with the same wallpaper that lined the remainder of the room (red brick with white, irregular, short vertical and longer horizontal lines representing the cement between bricks), prevented direct illumination from the lamp into the eyes of the subject. The luminance was not homogeneous within the pitchroom, but decreased monotonically on the interior surface facing the subject, from $7.5 \mathrm{~mL}$ at the top to $0.5 \mathrm{~mL}$ at the bottom (the bottom was $26 \mathrm{in}$. from the floor of the exterior room when the pitchroom was erect), with the average at $3.4 \mathrm{~mL}$. The luminance of the two-line pitched-from-vertical stimulus viewed during the light phase in Experiment 3 was $0.01 \mathrm{~mL}$.

\section{RESULTS}

In all three experiments light adaptation was rapid; the course of dark adaptation was much slower. Light adaptation was virtually complete before the first measurement at $1 \mathrm{~min}$ of exposure to the pitched field. The extent of the change in VPEL during dark adaptation in the cross-adaptation condition was $85 \%$ of that in the sameeye condition. Average values of dark adaptation in all three cases approximated a negatively accelerated exponential. Time constants averaged $4 \mathrm{~min}$ following exposure to the illuminated pitchroom in Experiments 1 and 2 and was somewhat less following exposure to the twoline stimulus; the extent of the change was about $30 \%$ 
Table 1

Measurements of Visually Perceived Eye Level (VPEL)

\begin{tabular}{|c|c|c|c|c|c|c|c|c|c|c|c|c|c|c|c|}
\hline \multirow[b]{4}{*}{ Subject } & \multirow{4}{*}{$\begin{array}{c}\text { Light } \\
\text { Adapt } \\
\text { Eye/ } \\
\text { Test Eye }\end{array}$} & \multirow[b]{4}{*}{ Visual Pitch } & \multicolumn{7}{|c|}{ VPEL Measurements } & \multicolumn{6}{|c|}{ During Dark Adapt } \\
\hline & & & \multicolumn{4}{|c|}{ Predark } & \multirow{2}{*}{\multicolumn{3}{|c|}{ Light }} & \multirow{2}{*}{\multicolumn{3}{|c|}{ Ranges }} & \multirow{2}{*}{\multicolumn{3}{|c|}{$\begin{array}{c}\text { Best-Fit Values } \\
\mathrm{VPEL}=a+b e^{-t / \tau}\end{array}$}} \\
\hline & & & \multicolumn{2}{|c|}{$1 \mathrm{st}$} & \multicolumn{2}{|c|}{ 2nd } & & & & & & & & & \\
\hline & & & $M$ & $\overline{S D}$ & $M$ & $S D$ & $M$ & $S D$ & Slope & $\mathrm{L}_{4}-\mathrm{D}_{20}$ & $\mathrm{D}_{0}-\mathrm{D}_{20}$ & $S D$ & $a$ & $b$ & $\tau$ \\
\hline W.L. & $\begin{array}{l}\text { Same } \\
\text { Same } \\
\text { Cross }\end{array}$ & $\begin{array}{l}20^{\circ} \text { Topforward } \\
30^{\circ} \text { Topbackward } \\
30^{\circ} \text { Topbackward }\end{array}$ & $\begin{array}{l}-4.4 \\
-5.1 \\
-4.0\end{array}$ & $\begin{array}{l}0.8 \\
1.2 \\
1.2\end{array}$ & $\begin{array}{l}-4.9 \\
-5.2 \\
-4.1\end{array}$ & $\begin{array}{l}1.4 \\
0.5 \\
1.3\end{array}$ & $\begin{array}{l}+15.4 \\
-21.6 \\
-18.8\end{array}$ & $\begin{array}{l}1.3 \\
0.9 \\
0.7\end{array}$ & & $\begin{array}{c}+18.2 \\
-19.4 \\
*\end{array}$ & & & $\begin{array}{l}-2.5 \\
-3.0 \\
-4.1\end{array}$ & & $\begin{array}{l}3.90 \\
4.76 \\
4.18\end{array}$ \\
\hline C.Z. & $\begin{array}{l}\text { Same } \\
\text { Same } \\
\text { Cross }\end{array}$ & & $\begin{array}{l}-4.9 \\
-5.9 \\
-5.7\end{array}$ & $\begin{array}{l}2.2 \\
1.3 \\
1.1\end{array}$ & $\begin{array}{l}-4.5 \\
-5.8 \\
-5.7\end{array}$ & $\begin{array}{l}1.3 \\
1.5 \\
0.6\end{array}$ & & $\begin{array}{l}1.3 \\
1.6 \\
0.8\end{array}$ & +0.76 & $\begin{array}{c}+20.5 \\
-16.0 \\
*\end{array}$ & & & & & $\begin{array}{l}5.13 \\
9.26 \\
8.00\end{array}$ \\
\hline L.M. & & & $\begin{array}{l}-1.0 \\
-0.5 \\
-0.3\end{array}$ & $\begin{array}{l}0.9 \\
0.2 \\
0.8\end{array}$ & $\begin{array}{l}-2.1 \\
-0.1 \\
-1.7\end{array}$ & $\begin{array}{l}1.2 \\
0.4 \\
1.3\end{array}$ & $\begin{array}{l}+21.3 \\
-21.0 \\
-18.3\end{array}$ & $\begin{array}{l}1.1 \\
1.7 \\
1.3\end{array}$ & +0.85 & $\begin{array}{c}+25.4 \\
-15.3 \\
*\end{array}$ & $\begin{array}{r}+11.5 \\
-9.9 \\
-7.5\end{array}$ & & & & $\begin{array}{l}6.94 \\
2.07 \\
1.51\end{array}$ \\
\hline I.P. & $\begin{array}{l}\text { Same } \\
\text { Same } \\
\text { Cross }\end{array}$ & & $\begin{array}{l}-3.3 \\
-3.3 \\
-1.3\end{array}$ & $\begin{array}{l}0.9 \\
1.0 \\
0.5\end{array}$ & $\begin{array}{l}-1.1 \\
-8.6 \\
-5.5\end{array}$ & $\begin{array}{l}1.3 \\
2.4 \\
3.4\end{array}$ & & $\begin{array}{l}1.0 \\
2.3 \\
0.8\end{array}$ & & $\begin{array}{c}+11.5 \\
-10.3 \\
*\end{array}$ & & & & $\begin{array}{r}+7.0 \\
-11.4 \\
-9.7\end{array}$ & $\begin{array}{r}3.62 \\
19.61 \\
10.64\end{array}$ \\
\hline G.V. & $\begin{array}{l}\text { Same } \\
\text { Same } \\
\text { Cross }\end{array}$ & $\begin{array}{l}20^{\circ} \text { Topforward } \\
30^{\circ} \text { Topbackward } \\
30^{\circ} \text { Topbackward }\end{array}$ & $\begin{array}{l}-6.4 \\
-2.4 \\
-5.8\end{array}$ & $\begin{array}{l}3.4 \\
1.6 \\
1.0\end{array}$ & $\begin{array}{l}-7.2 \\
-2.4 \\
-5.3\end{array}$ & $\begin{array}{l}3.1 \\
1.1 \\
0.7\end{array}$ & $\begin{array}{l}+0.0 \\
-7.0 \\
-8.1\end{array}$ & $\begin{array}{l}1.8 \\
1.2 \\
1.0\end{array}$ & +0.14 & $\begin{array}{c}+7.1 \\
-1.5 \\
*\end{array}$ & & $\begin{array}{l}+ \\
\dagger \\
+\end{array}$ & $\begin{array}{l}\dagger \\
\dagger \\
\dagger\end{array}$ & $\begin{array}{l}+ \\
+ \\
+\end{array}$ & $\begin{array}{l}\dagger \\
\dagger \\
+\end{array}$ \\
\hline S.W. & $\begin{array}{l}\text { Same } \\
\text { Same } \\
\text { Cross }\end{array}$ & $\begin{array}{l}20^{\circ} \text { Topforward } \\
30^{\circ} \text { Topbackward } \\
30^{\circ} \text { Topbackward }\end{array}$ & $\begin{array}{l}-2.2 \\
-1.0 \\
-2.9\end{array}$ & $\begin{array}{l}1.4 \\
1.0 \\
1.9\end{array}$ & $\begin{array}{l}-3.3 \\
-1.7 \\
-4.0\end{array}$ & $\begin{array}{l}1.0 \\
0.8 \\
2.0\end{array}$ & $\begin{array}{r}+7.7 \\
-17.1 \\
-18.6\end{array}$ & $\begin{array}{l}0.9 \\
1.1 \\
0.6\end{array}$ & +0.50 & $\begin{array}{c}+10.4 \\
-15.3 \\
*\end{array}$ & $\begin{array}{r}+7.2 \\
-12.3 \\
-9.9\end{array}$ & $\begin{array}{l}1.3 \\
1.1 \\
1.3\end{array}$ & $\begin{array}{l}-2.7 \\
-3.4 \\
-4.2\end{array}$ & $\begin{array}{r}+8.5 \\
-13.9 \\
-9.4\end{array}$ & $\begin{array}{l}3.16 \\
1.80 \\
3.48\end{array}$ \\
\hline $\begin{array}{l}\text { Average } \\
\text { (6 Os.) }\end{array}$ & $\begin{array}{l}\text { Same } \\
\text { Same } \\
\text { Cross }\end{array}$ & $\begin{array}{l}20^{\circ} \text { Topforward } \\
30^{\circ} \text { Topbackward } \\
30^{\circ} \text { Topbackward }\end{array}$ & $\begin{array}{l}-3.7 \\
-3.0 \\
-3.3\end{array}$ & $\begin{array}{l}1.6 \\
1.2 \\
1.1\end{array}$ & $\begin{array}{l}-3.9 \\
-4.0 \\
-4.4\end{array}$ & $\begin{array}{l}1.6 \\
1.1 \\
1.4\end{array}$ & $\begin{array}{l}+12.2 \\
-18.8 \\
-16.7\end{array}$ & $\begin{array}{l}1.2 \\
1.5 \\
0.9\end{array}$ & +0.62 & $\begin{array}{c}+15.5 \\
-13.0 \\
*\end{array}$ & $\begin{array}{l}+9.2 \\
-9.9 \\
-8.3\end{array}$ & $\begin{array}{l}2.0 \\
2.0 \\
1.9\end{array}$ & & & \\
\hline $\begin{array}{l}\text { Average } \\
(5 \text { Os.) }\end{array}$ & $\begin{array}{l}\text { Same } \\
\text { Same } \\
\text { Cross }\end{array}$ & $\begin{array}{l}20^{\circ} \text { Topforward } \\
30^{\circ} \text { Topbackward } \\
30^{\circ} \text { Topbackward }\end{array}$ & $\begin{array}{l}-3.2 \\
-3.2 \\
-2.8\end{array}$ & $\begin{array}{l}1.2 \\
0.9 \\
1.1\end{array}$ & $\begin{array}{l}-3.2 \\
-4.3 \\
-4.2\end{array}$ & $\begin{array}{l}1.2 \\
1.1 \\
1.7\end{array}$ & $\begin{array}{l}+14.7 \\
-21.1 \\
-18.4\end{array}$ & $\begin{array}{l}1.1 \\
1.5 \\
0.8\end{array}$ & +0.72 & $\begin{array}{c}+17.2 \\
-15.3 \\
*\end{array}$ & $\begin{array}{r}+9.9 \\
-11.8 \\
-9.2\end{array}$ & $\begin{array}{l}1.7 \\
2.2 \\
2.1\end{array}$ & $\begin{array}{l}-3.6 \\
-6.0 \\
-4.3\end{array}$ & $\begin{array}{l}+10.4 \\
-13.0 \\
-10.9\end{array}$ & $\begin{array}{l}4.33 \\
3.55 \\
3.56\end{array}$ \\
\hline
\end{tabular}

Note-Measurements of VPEL in darkness at the beginning of the session against the erect dark pitchroom are displayed in the column headed "Predark 1st," measurements against the pitched dark pitchroom are in the column headed "Predark 2nd," and measurements against the illuminated pitchroom are in the column headed "Light." Each VPEL value for a given condition is the mean for that condition across all of the different times. Positive and negative values of VPEL are settings above and below true eye level, respectively. The value of VPEL at each of the different times is displayed separately for each condition in Figures 4 and 5.

Each $S D$ value is the average standard deviation value across all of the times in the given condition; this average is taken of the individual standard deviations obtained separately at each time in the given condition; each of these individual standard deviations is the variation of the separate measurements among the individual trials at a given time in the given condition.

Values in the column headed "Slope" are the difference in Experiment 1 between the VPEL values of the illuminated pitchroom in the sameeye condition divided by the difference in the two pitches $\left(50^{\circ}\right)$.

The column headed " $\mathrm{L}_{4}-\mathrm{D}_{20}$ " is the difference between the VPEL during the last minute of exposure to the illuminated pitchroom and the VPEL measured during the 20 th minute in darkness. " $D_{0}-D_{20}$ " is the range over which VPEL changed in darkness following extinction of pitchroom illumination from the first measurement in darkness to the last.

The curves representing the best-fitting values of the exponential decay function VPEL $=a+b e^{-t / \tau}$ during dark adaptation are displayed in Figures 4 and 5 . The units for all measured values and for best-fitting values for $a$ and $b$ are in degrees visual angle ( + and - indicate values above and below true eye level, respectively), units for $\tau$ are in minutes. Although fits were obtained in G.V.'s case and are displayed in the figures, the variation of VPEL during dark adaptation was too shallow to yield meaningful parameters. *No value of $\mathrm{L}_{4}$ available for the right eye. tSee Note 3 .

less. The description below describes these results in more detail.

\section{Steady-State VPELs With Pitched Visual Fields}

The average VPEL values measured during the last minute of light adaptation are presented at the bottom of Table 1. Figure 3 a displays the VPEL values for the two conditions with the fully illuminated pitchroom ("sameeye," "cross-adaptation"); Figure $3 \mathrm{~b}$ displays the values for the two-line condition. The main effects during pitch exposure in the same-eye condition with the illuminated pitchroom and the two-line condition are closely similar to those reported in our earlier work (cf. Figure 1c), with the average VPEL deviating from true eye level by approximately $60 \%$ of the angle of the pitched visual field. The larger VPEL with topbackward pitch corresponds to the fact that the influence of pitch is linear with a $y$ intercept close to zero $\left(-0.2^{\circ}\right)$, as in the earlier work. The average effect during the light period for the left eye in the cross-adaptation condition is similar (Table 1) to the value with the right eye in the same-eye condition $\left(-18.8^{\circ}\right.$ vs. $\left.-16.7^{\circ}\right)$.

Four of the present subjects also served in the earlier experiments, and a comparison of slopes of their VPELversus-pitch functions in the two experiments provides an additional opportunity to note the order of individual consistency over time to which we referred earlier. L.M.'s 

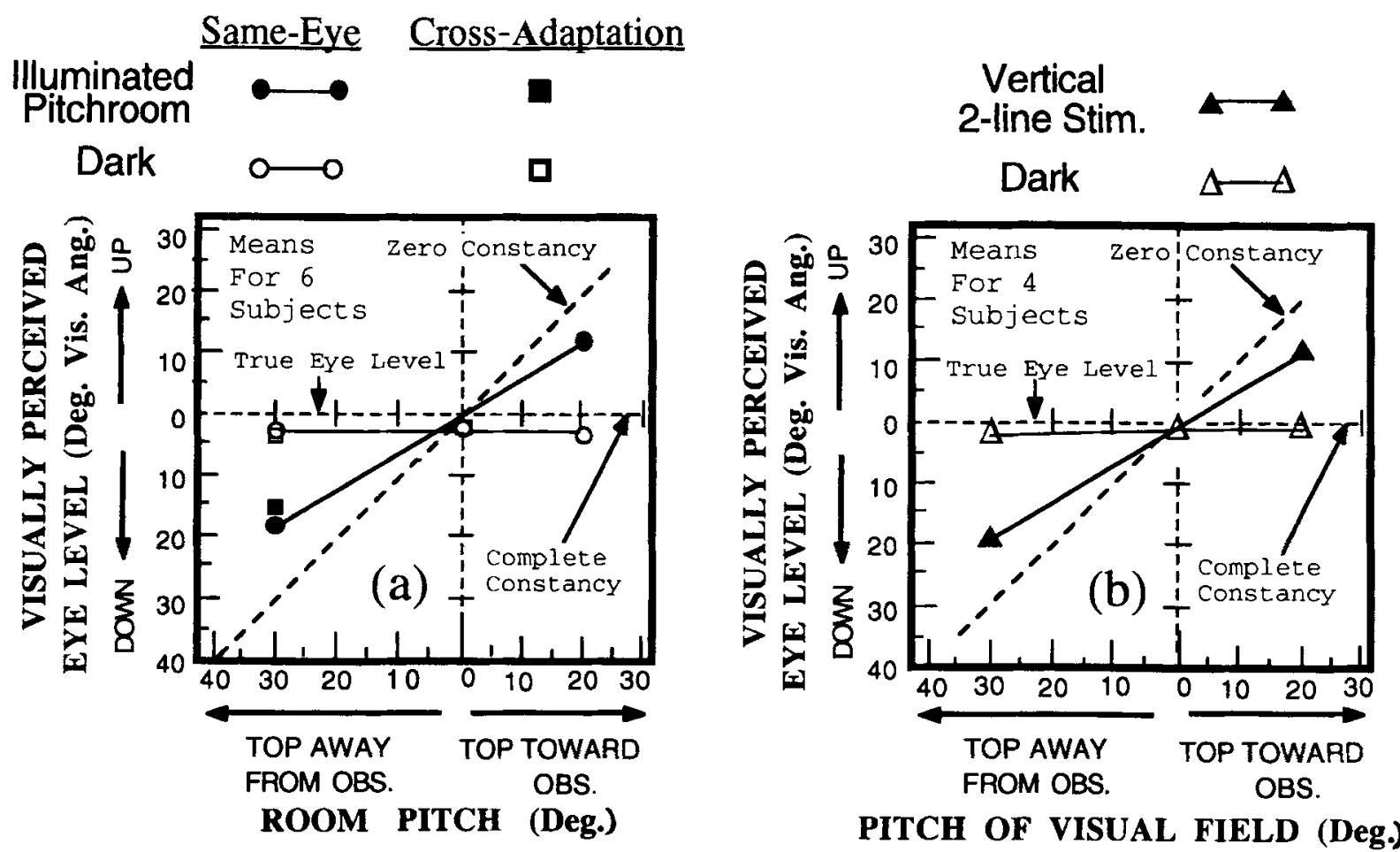

Figure 3. (a) Experiments 1 and 2: Visually perceived eye level measured against illuminated pitchroom pitched at either $30^{\circ}$ topbackward

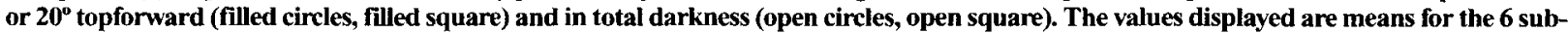
jects. The open and filled squares (cross-adaptation) were measurements on the left eye. All other measurements were on the right eye. (b) Experiment 3: Visually penceived eye level measured against the two-line stimulus pitched at either $30^{\circ}$ topbackward or $20^{\circ}$ top forward (filled triangles) and in total darkness (open triangles). The values displayed are means for the 4 subjeets.

slope in the earlier experiment (Matin \& Li, 1989b, 1992 c) was +0.84 , compared with +0.85 in the present experiment (Table 1). For W.L. the values were +0.62 versus +0.74 , for I.P. the values were +0.74 versus +0.74 , and for $G$.V. the values were +0.45 versus +0.14 (the change in G.V's slope is the largest we've ever measured). For the 2 subjects in the present experiment who were also used in the previous experiment with the twoline stimulus, the comparisons are +0.51 versus +0.64 for W.L. and +0.64 versus +0.75 for L.M., for the previous and present slopes, respectively.

The average slope of the VPEL-versus-pitch function with the two-line condition is indistinguishable from the average slope with the illuminated pitchroom (slopes of $+0.61 \mathrm{vs} .+0.62$ ). This is probably largely related to the use of different groups of subjects in the two experiments: Average VPELs for the 3 subjects who were employed in both conditions were +0.61 and +0.79 for the two-line and illuminated pitchroom experiments, respectively, with the smaller slope for the two-line stimulus, as was reported previously (Matin \& Li, 1992c, $1994 a, 1994 b)$

\section{VPEL During Light Adaptation}

As noted above, the VPEL values obtained during exposure to the illuminated pitchroom are similar to those in our previous reports, although in those reports time after exposure onset was not closely controlled. The effect of pitch on VPEL for the individual subjects during light adaptation appears in Figures 4 (same-eye condition), 5 (cross-adaptation condition), and 6 (two-line condition) as the large separation between the VPEL values in the light period (shown at 21-26 min on the abscissa) from baseline values in the dark. Following the onset of illumination of the pitched visual field, VPEL changed sharply from its dark-adapted value to a stable value during the 5-min period of exposure to illumination; there is no indication of a systematic departure from randomness during the exposure period in any of the three experiments. Light adaptation was essentially complete by 1 min of exposure.

\section{Baseline VPEL in Darkness}

The VPEL values for individual subjects, measured in darkness at the beginning of the session, are displayed in Figures 4, 5, and 6 immediately to the right of the arrow denoting the beginning of the session; average values across subjects are displayed in Figure 7. Each of the eight data points is the average of four measurements (two taken at the same time in each of two sessions). The VPEL values against the erect room and against the pitched room are listed in Tables 1 and 2 as 


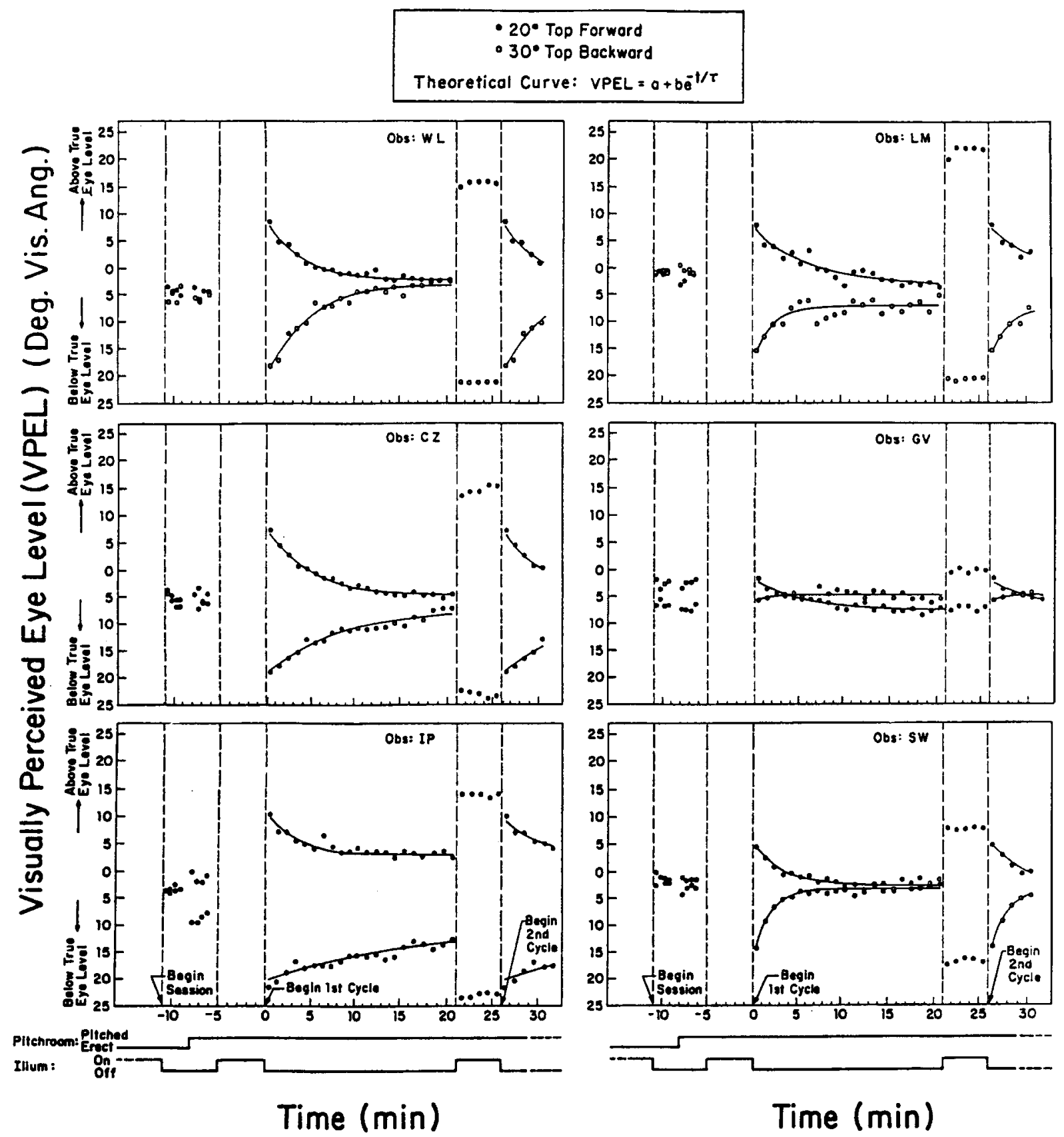

Figure 4. Same-eye experiment: VPEL during light and dark adaptation is displayed separately for each of 6 subjects in sessions involving $20^{\circ}$ topforward pitch (filled circles) and $30^{\circ}$ topbackward pitch (unfilled circles). All measurements were on the right eye of the subject; the left eye was occluded. The measurements follow the sequence described in Figure 2. Each displayed value in darkness and in the illuminated pitchmom is the mean of four settings (one in each of four cycles) except for I.P., where the values are means of eight measurements. The curves drawn through the points are the best-fitting exponentials; values for best fit are displayed in Table 1.

first and second predark VPEL measurements, respectively.

The dark VPELs are below true eye level in each of the 144 cases in Experiments 1 and 2 with only three negligible exceptions, and in 48 of the 64 cases in Experiment 3 , with all 16 exceptions due to Subject W.H. This result agrees with earlier reports (Matin \& Fox, 1986, 1989; Matin \& Li, 1989b, 1992c; Stoper \& Cohen, 1986). The average values of the second set of dark VPEL values are slightly lower than those of the first set for all five conditions (Figure 7). This result is to be expected, since the second set of measurements in darkness was 

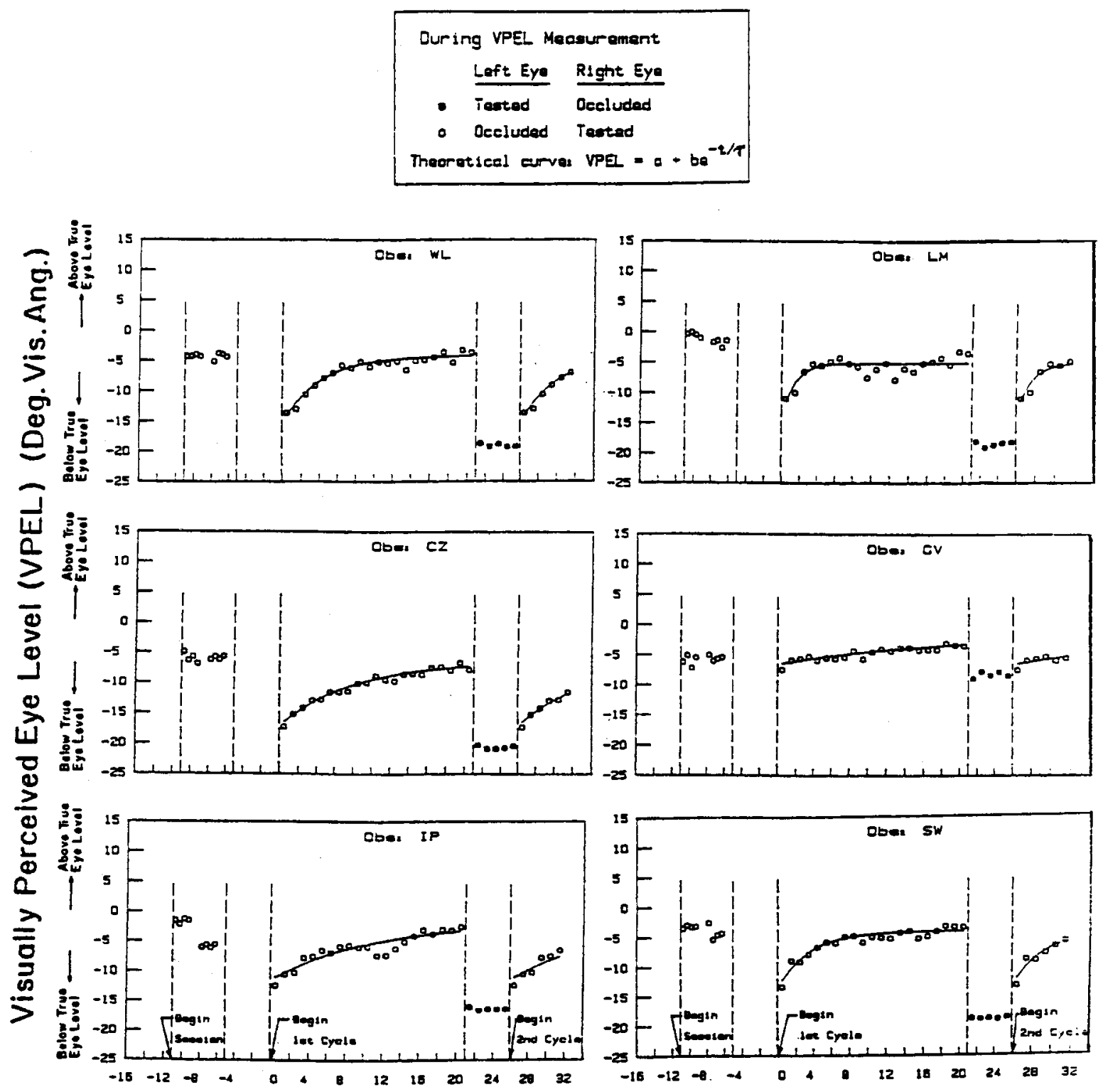

Pitchroom:
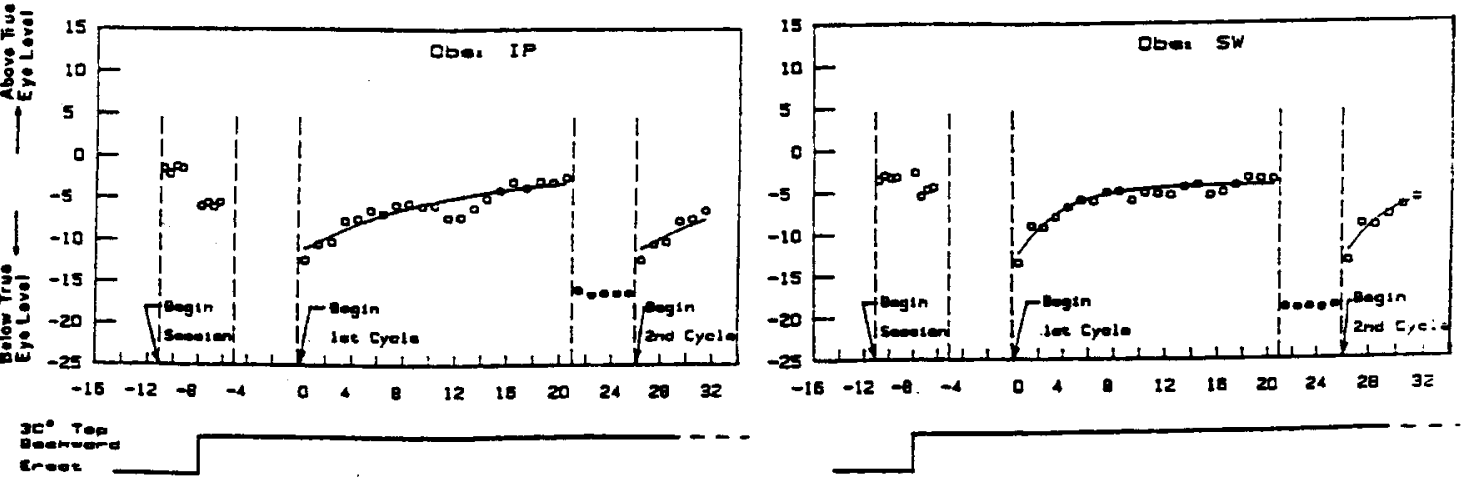

Illum.:

Left Eyc

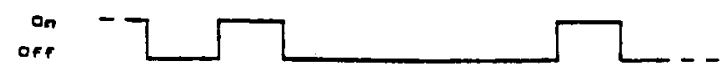

\section{Time (min)}

\section{Time (min)}

Figure 5. Cross-adaptation experiment: VPEL during light and dark adaptation is displayed separately for each of 6 subjects in sessions involving $30^{\circ}$ topbackward pitch. All measurements during illumination were on the left eye of the subject; the right eye was occluded. (No measurements were taken during the first 5-min period of monocular pitch exposure by the left eye.) All measurements during darkness were on the right eye; the left eye was occluded. The measurements follow the sequence described in Figure 2. Each displayed value in darkness and in the illuminated pitchroom is the mean of four settings (one in each of four cycles). The curves drawn through the points are the best-fitting exponentials; values for best fit are displayed in Table 1.

taken later than the first set following normal exposure to the erect environment exterior to the pitchroom, and also since the VPEL in the presence of an erect environment is typically above the VPEL in darkness.

The purpose of separate treatment of the dark VPELs against the erect pitched room was concern with the pos- sibilities that the room was not truly darkened or that the subjects were somehow employing knowledge of pitchroom orientation in making their settings. Any such influence should be revealed by a systematic difference between the settings against the erect and pitched rooms in darkness, in which the second value lies below the 


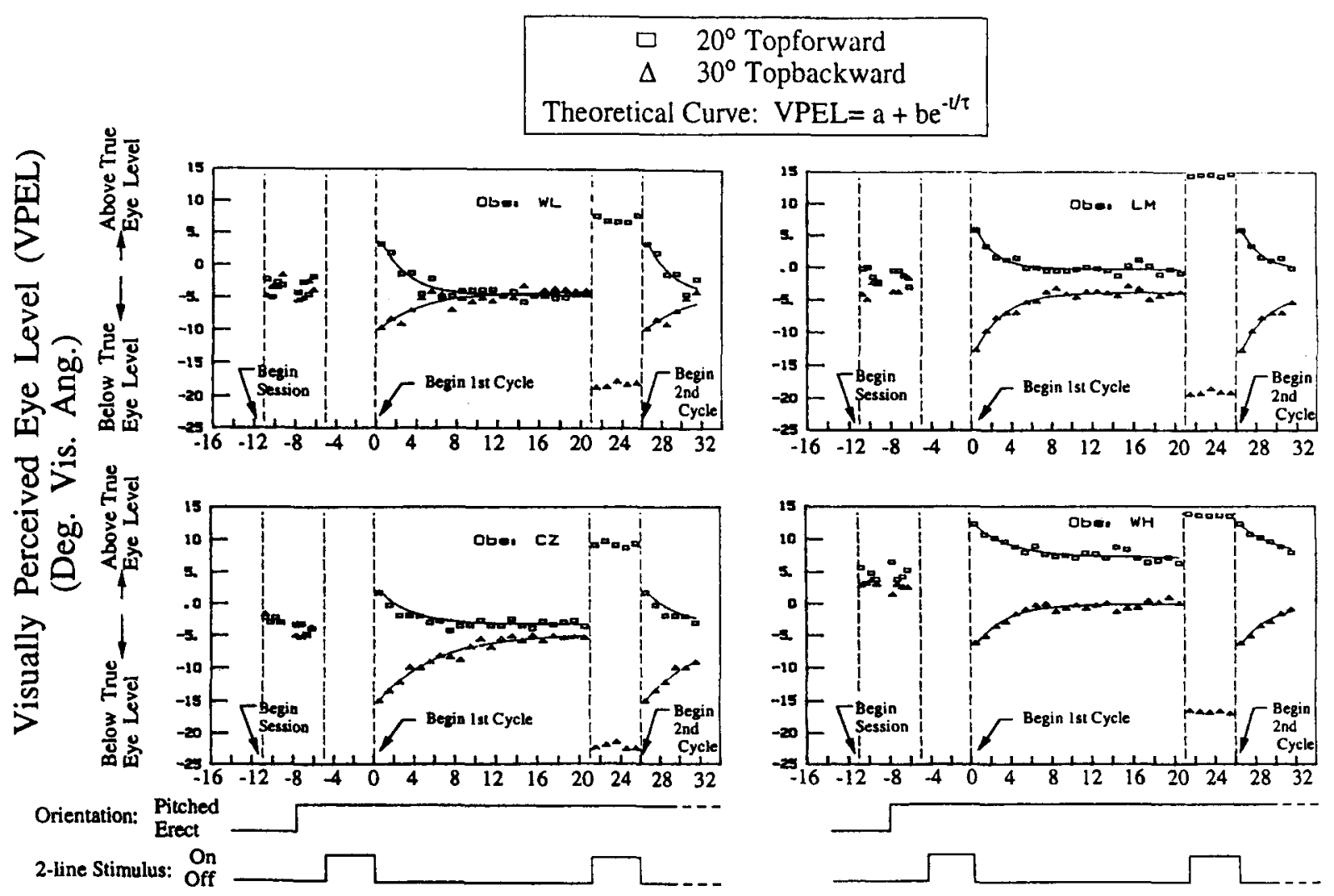

Time (Min.)

Figure 6. Same as Figure 4 for Experiment 3 with the two-line stimulus.

first value in the sessions with the room pitched topbackward, and above the first value in the sessions with the room pitched topforward. With the exception of Subject I.P., such a result does not appear. The fact that no other subject displayed a similar constellation of effects strongly indicates that I.P.'s result was not a result of failing to darken the room during each measurement. The average result in the cross-adaptation experiment is essentially identical to the result in the same-eye experiment, and, again, only I.P.'s results show such an effect. ${ }^{2}$

\section{VPEL During Dark Adaptation}

\section{Dark Adaptation of VPEL}

\section{for the Previously Exposed Eye}

Following extinction of illumination, with the exception of Subject G.V., ${ }^{3}$ the change during the first minute in darkness was precipitous and continued at a negatively accelerated rate during the 20 -min dark period, although most of the change was complete within $10 \mathrm{~min}$. The change is toward lower physical elevations during dark periods following exposure to topforward pitch and toward higher elevations following exposure to topbackward pitch. The entire range covered during dark adaptation is measured by the difference in VPEL between the value at the end of the period of exposure to pitch ( $\mathrm{L}_{4}$; Figure 2 ) and the last value measured during dark adaptation $\left(\mathrm{D}_{20}\right)$ and is displayed in Table 1 as $\mathrm{L}_{4}-\mathrm{D}_{20}$. Although the topforward pitch deviated slightly less from veridicality than did the topbackward pitch $\left(20^{\circ}\right.$ vs. $\left.30^{\circ}\right)$, the average $L_{4}-D_{20}$ range is similar following exposure to both $\left(15.5^{\circ}\right.$ vs. $13.0^{\circ}$; Table 1$)$; this corresponds to the fact that the VPEL values at the end of dark adaptation generally lie approximately $4^{\circ}$ below true eye level.

The precipitous initial drop from the value during illumination is numerically equal to the difference between the last measurement at the end of the period of illumination and the first measurement in the dark period $\left(L_{4}-D_{0}\right)=\left(L_{4}-D_{20}\right)-\left(D_{0}-D_{20}\right)$; the average differences for this initial drop are $6.3^{\circ}$ and $3.1^{\circ}$ for the two same-eye conditions. Following exposure to the two different directions of pitch, the VPEL values reached at the end of the 20-min period of dark adaptation for a given individual are fairly close to each other with the exception of Subject I.P., indicating essential completeness of the dark adaptation process within the 20 -min period.

\section{Dark Adaptation of VPEL for the Nonexposed Eye}

The form of the dark adaptation functions in the crossadaptation condition is the same as that in the same-eye 
EXP.1: Illum. Ptchrm Same-Eye

(0) $20^{\circ}$ Top Forward

$\Delta \quad 30^{\circ}$ Top Backward

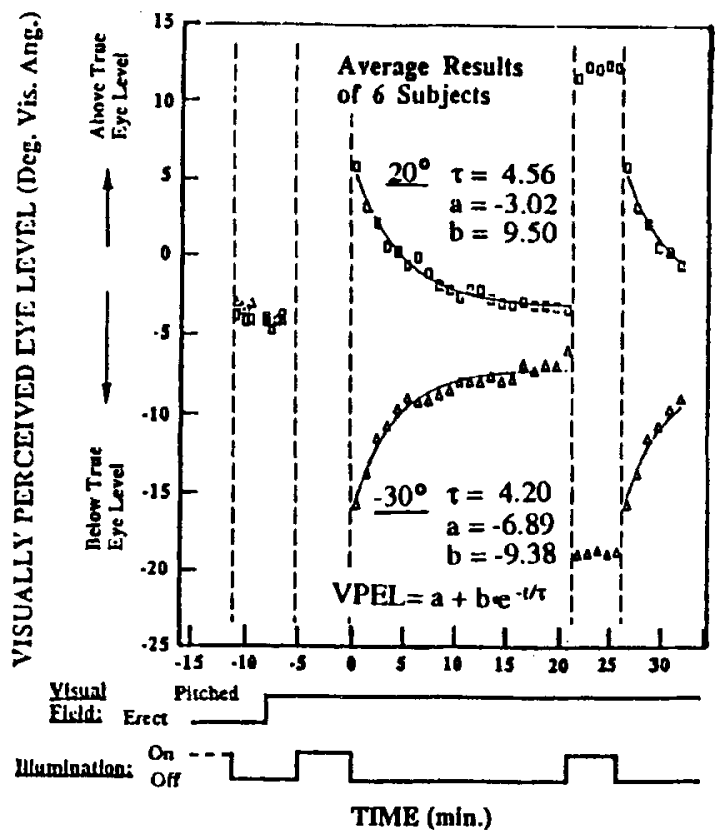

(a)
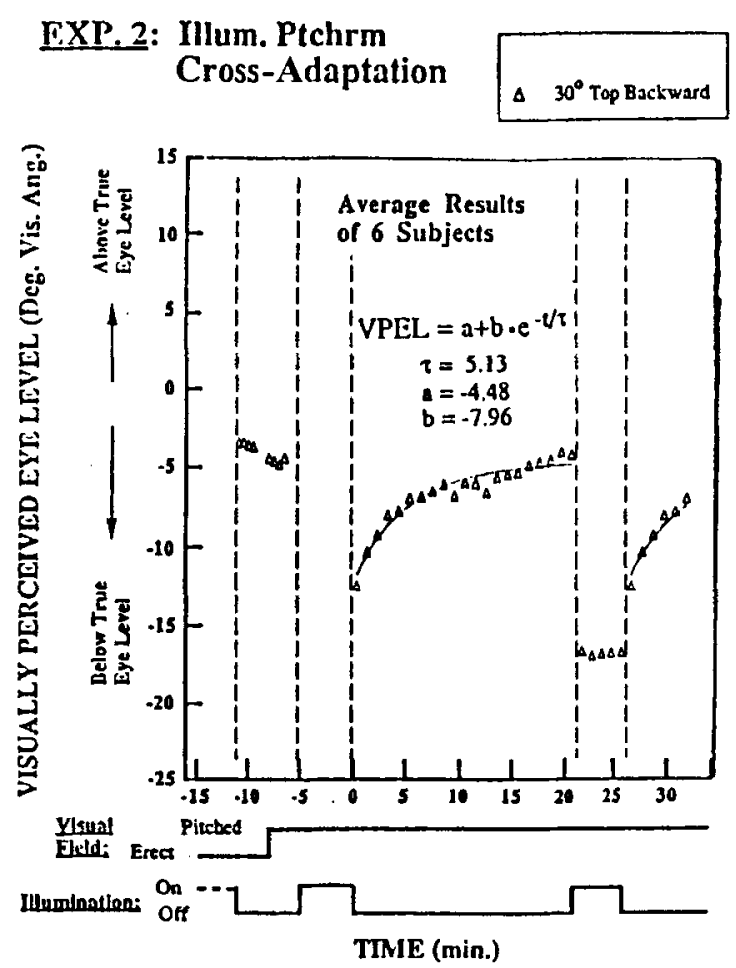

(b)

EXP. 3: 2-Line Stim. Same-Eye \begin{tabular}{ll}
\hline & $20^{\circ}$ Top Forwars \\
$\Delta$ & $30^{\circ}$ Top Bactiwars
\end{tabular}

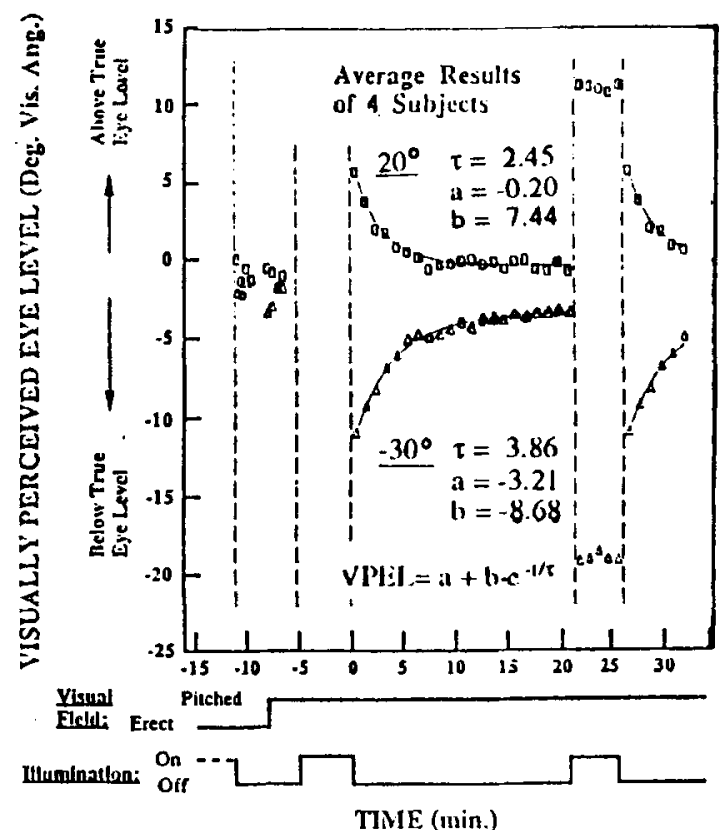

(c)

Figure 7. (a) Average values for the 6 subjects in Experiment 1; (b) Average values for the 6 subjects in Experiment 2; (c) Average values for the 4 subjects in Experiment 3. (Illum. Ptchrm, illuminated pitchroom.) 
condition. Since no VPEL measurements could be made on the right eye during exposure to the illuminated visual field, the initial drop from the value in the light to the first dark value is not available. However, the difference between the first and last measurements in darkness, $D_{0}-D_{20}$, provides a basis for comparison with the sameeye condition. Following $30^{\circ}$ topbackward pitch, the change in VPEL during dark adaptation in the cross-adaptation condition averaged $20 \%$ less than that in the comparable same-eye condition $\left(-9.2^{\circ}\right.$ vs. $-11.8^{\circ}$; Table 1$)$.

The deviation of VPEL for the right eye from its darkadapted base level is about $25 \%$ smaller in the first minute during dark adaptation following extinction of the illumination to the left eye in the pitched room (cross-adaptation experiment) than it is following extinction of the exposure to pitch with the right eye (same-eye experiment). This result is visible in Figures 4,5 , and 7 , but is clearer in Figure 8 , which plots the minute-by-minute tracks of VPEL during the dark periods in the two experiments directly against each other. In Figure 8, a point above the main diagonal indicates that the influence of pitch on VPEL was larger in the same-eye experiment than in the cross-adaptation experiment; the starting points (first minute) for each subject (Figure 8a) and the average across subjects (Figure $8 b$ ) lie above the main diagonal. The results remain above the main diagonal for a period, after which the paired VPEL values for all but one of the individual subjects appear to fluctuate randomly above and below the main diagonal; the average, however, remains above the main diagonal (Figure $8 b$ ), a result that holds even with I.P.'s results eliminated. The approximation to linearity in Figure 8 indicates that there is no serious divergence in the form of the dark adaptation function when previous exposure to pitch is in the measured eye only or in the contralateral eye only. Scaling is confirmed by the fact that the best-fitting slopes of four of the six data sets in Figure 8 were $+0.59,+0.61,+0.80$, and +0.86 , for Subjects L.M., W.L., S.W., and C.Z., respectively, with high positive linear correlations between the two time tracks $(+0.74,+0.97,+0.93$, and +0.97 , respectively). Slopes for I.P. and G.V. were +1.03 and -0.05 , with linear correlations of +0.93 and -0.04 , respectively; the peculiarity of G.V.'s results (all at the upper right in Figure 8) derives from the fact that measurement noise appears to have hidden his shallow time functions. The slope of the average VPEL-versus-VPEL function in Figure $8 \mathrm{~b}$ is +0.85 . Values less than +1.00 indicate shallower dark adaptation functions following exposure to the contralateral eye than to the same eye in which the measurements were made in darkness.

\section{Dark Adaptation of VPEL Following \\ Exposure to the Two-Line Stimulus}

Individual dark adaptation functions following exposure to the two-line stimulus (Figure 6) as well as the average functions (Figure 7c) are similar to those following exposure to the illuminated pitchroom. The two-line functions approximate baseline somewhat earlier, as indicated by the horizontal segment in Figures $9 a$ and $9 b$ (from approximately $-10^{\circ}$ to $0^{\circ}$ on the abscissa), where VPEL for the two-line stimulus is not changing at the later times, although VPEL for the illuminated pitchroom continues to move toward baseline. Initial values during dark adaptation are not as far from the dark baseline for the two-line stimulus as for the illuminated pitchroom, as indicated by the fact that the VPELversus-VPEL values in Figure 9 are above the main diagonal for the $30^{\circ}$ topbackward condition and below the main diagonal for the $20^{\circ}$ topforward condition.

\section{Form of the Dark Adaptation Function}

The form of the change in VPEL during dark adaptation in each of the three experiments is well characterized by an exponential decay function,

$$
\operatorname{VPEL}(\theta, t)=a+b(\theta) e^{-t / \tau},
$$

where $\tau$ is the time constant of decay of VPEL from steady-state light-adapted to steady-state dark-adapted values, $b$ is a range (or scaling) constant that governs the magnitude and direction of the adaptive change, $a$ is the asymptotic dark value, and $\operatorname{VPEL}(\theta, t)$ is the value of VPEL at time $t$ in darkness following extinction of the visual field pitched by $\theta^{\circ}$. The least squares best fits to Equation 2 are the solid curves in Figures 4 and 5 . These curves and the parameters in Table 1 were obtained from fits constrained to the dark period and do not include the large drop from the value at the end of light adaptation to the first measurement in darkness. ${ }^{4}$

Average values of the best-fitting decay constants (Table 1) for the right eye are close to each other for the two directions of pitch in the same-eye experiment (4.33 and 3.55) and are identical following exposure to $30^{\circ}$ pitch by either eye (3.55 and 3.56). A major portion of the variation in the time constant for each subject is a consequence of the way in which cycle-to-cycle variability influences the average VPEL function. ${ }^{5}$

The average values of $a$ are close to the dark VPELs measured at the beginning of the session. This is both a reflection of the goodness of fit of the exponential function to the dark adaptation process and of the fact that the dark values were obtained shortly after normal exposure to the erect world outside the pitchroom. As expected also, values of $a$ in Table 1 are close to each other in the two experiments with exposure to the fully illuminated pitchroom $(-6.0$ and -4.3$)$ and become even closer if Subject I.P.'s results are not included $(-5.2$ and -4.9). The values of $a$ in Table 2 with the two-line stimulus for a different subject group are -0.2 and -3.1 .

Although both the average time constant, $\tau$, and level reached at the end of dark adaptation, $a$, are no different in cross-adaptation and same-eye conditions, the bestfitting scale constants, $b$, are uniformly smaller under cross-adaptation, averaging $16 \%$ less; this corresponds to the $16 \%$ range difference directly measured by $D_{0}-$ 


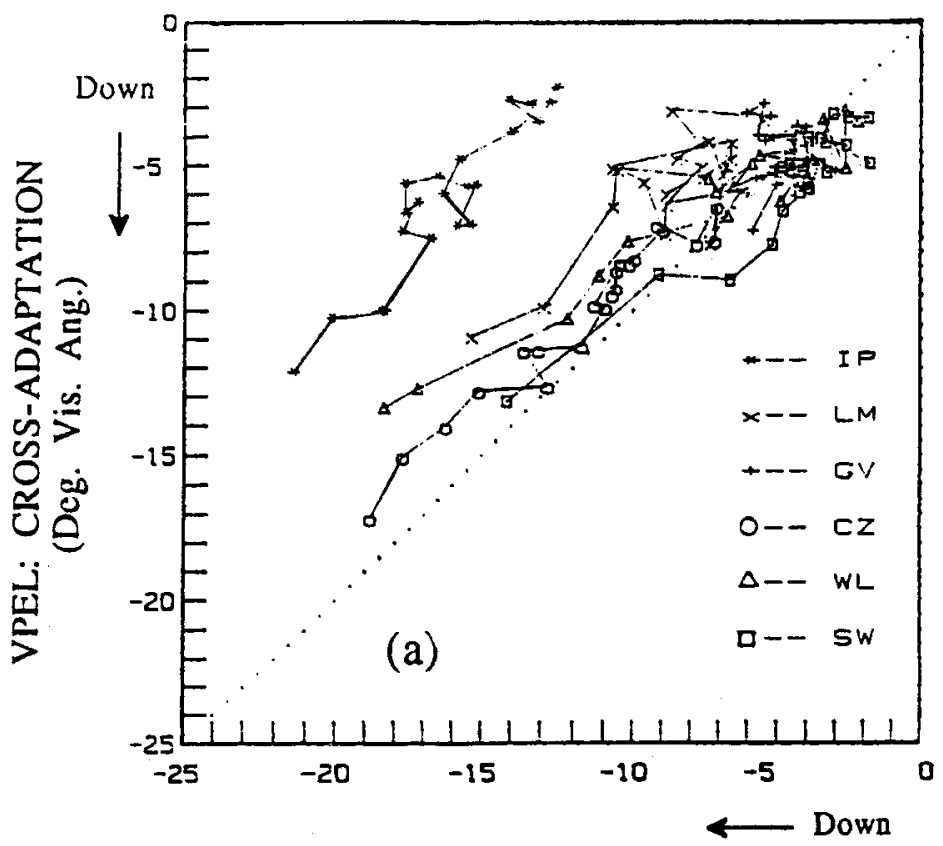

VPEL: SAME-EYE (Deg. Vis. Ang.)

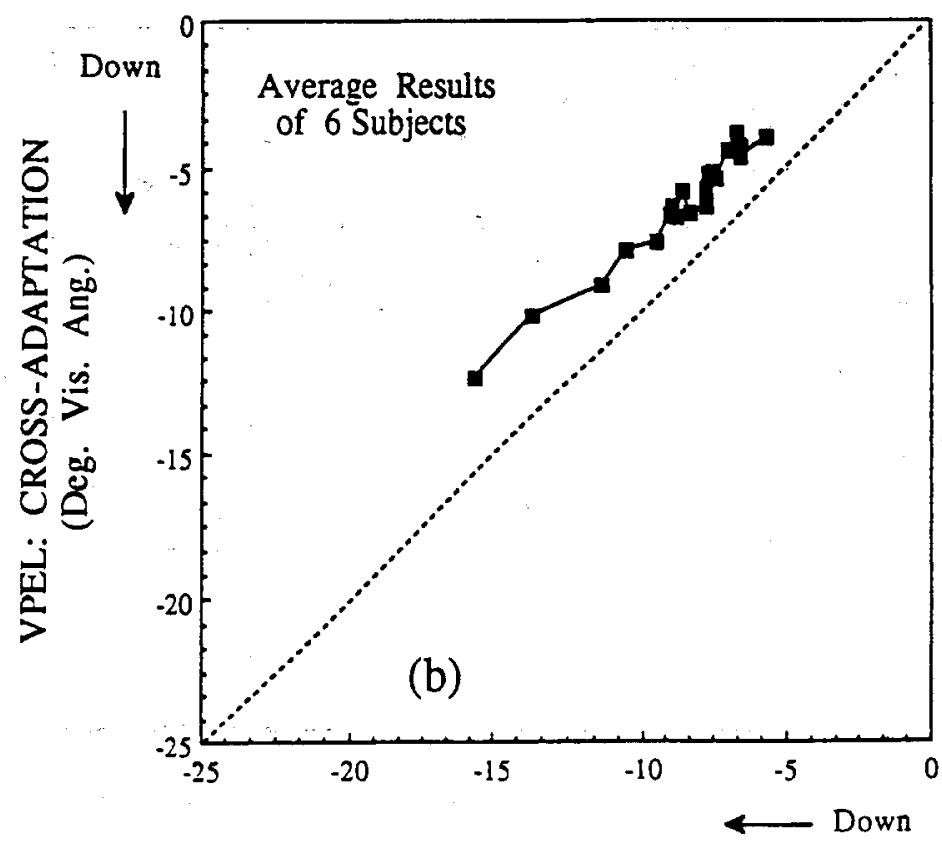

VPEL: SAME-EYE (Deg. Vis. Ang.)

Figure 8. (a) Visually perceived eye level (VPEL) for the right eye in darkness following $5 \mathrm{~min}$ of exposure of the left eye to the illuminated pitchroom (cross-adaptation experiment) is displayed on the ordinate; VPEL for the right eye following $5 \mathrm{~min}$ of exposure of the right eye to the illuminated pitchroom (same-eye experiment) is displayed on the abscissa. Pitch during illumination was $30^{\circ}$ topbackward in each case. A separate track is plotted for each of the 6 subjects. Each point in a track plots VPEL at the same time in the dark for the two experiments against each other. The points are connected in the order of the temporal sequence during the cycle; although the locations of the points are determined by the VPEL values, the first value in darkness is at the left for all subjects. (b) Average values for the 6 subjects in Experiments 1 and 2. 


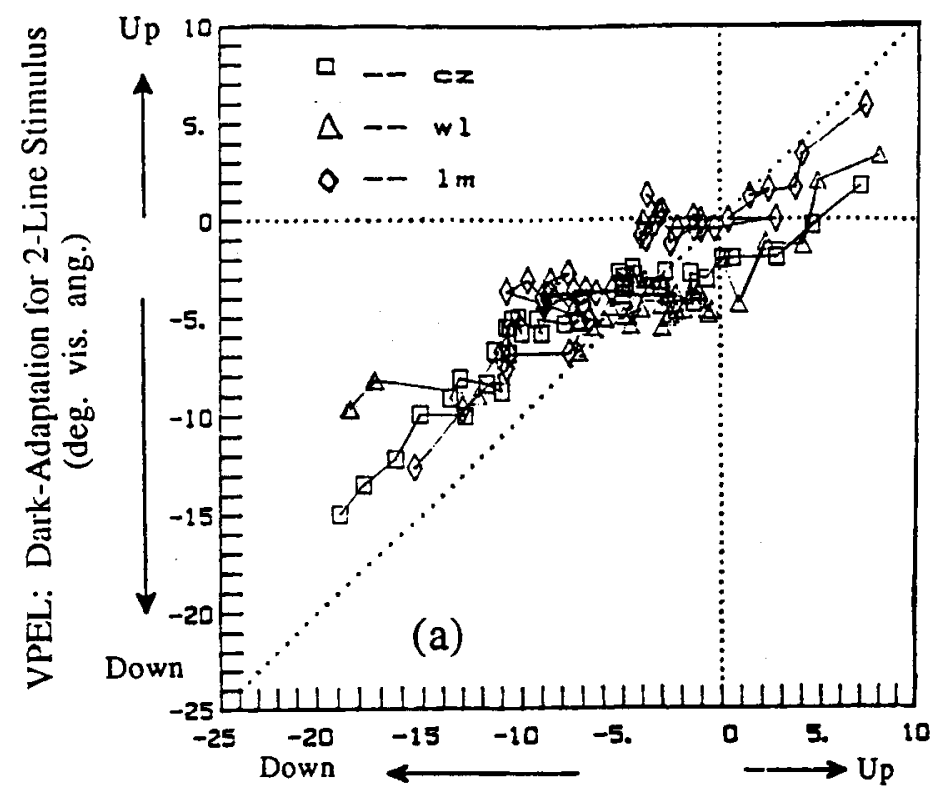

VPEL: Dark-Adaptation for Pitchroom (deg. vis. ang.)

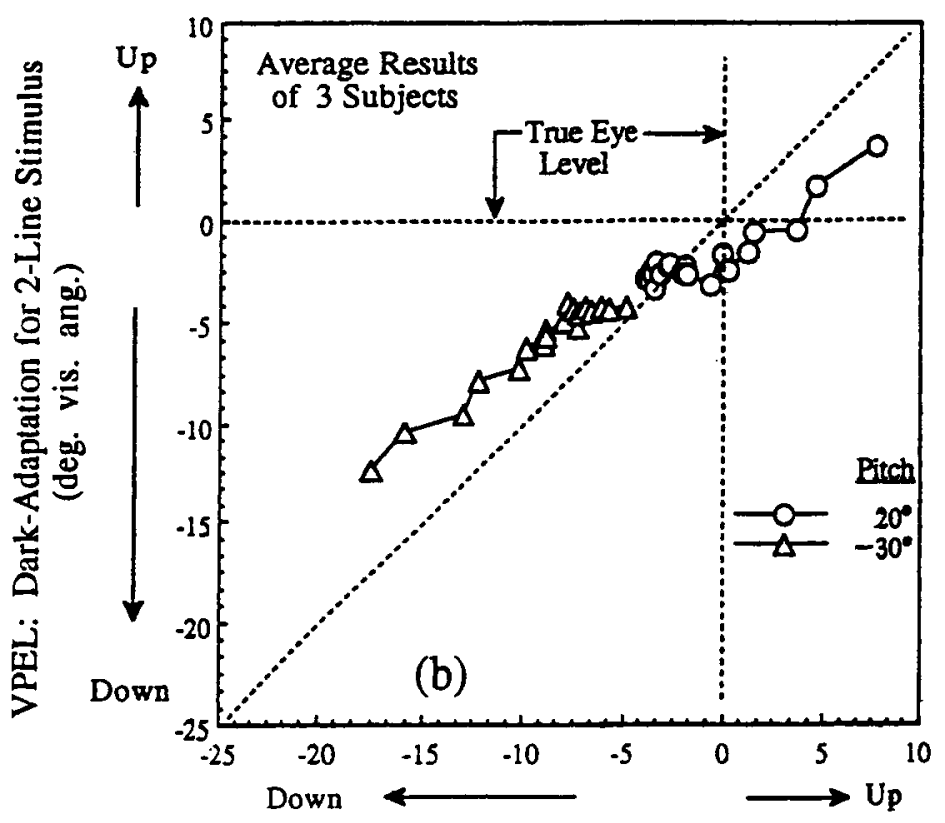

VPEL: Dark-Adaptation for Pitchroom (deg. vis. ang.)

Figure 9. VPEL-versus-VPEL (visually perceived eye level) functions for 3 subjects, plotting the results for Experiment 3 against those of Experiment 1. (a) Individual results. Each point plots the VPEL at a given time in the dark following extinction of the two-line stimulus (ordinate) against the VPEL at the same time in the dark following extinction of the fully illuminated pitchroom (abscissa). (b) Average results for the 3 subjects in (a) are plotted. Note that in both panels the leftmost set(s) of points refer to results following the $-30^{\circ}$ topbackward visual field; the rightmost set(s) of points refer to the $20^{\circ}$ topforward visual field. 
Table 2

Values of Visually Perceived Eye Level (VPEL) for Two-Line Visual Field Condition

\begin{tabular}{|c|c|c|c|c|c|c|c|c|c|c|c|c|c|c|}
\hline \multirow[b]{4}{*}{ Subject } & \multirow[b]{4}{*}{ Visual Pitch } & \multicolumn{7}{|c|}{ VPEL Measurements } & \multicolumn{6}{|c|}{ During Dark Adaptation } \\
\hline & & \multicolumn{4}{|c|}{ Predark } & \multirow{2}{*}{\multicolumn{3}{|c|}{ Light }} & \multirow{2}{*}{\multicolumn{3}{|c|}{ Ranges }} & \multirow{2}{*}{\multicolumn{3}{|c|}{$\begin{array}{c}\text { Best-Fit Values } \\
\text { VPEL }=a+b e^{-t / \tau}\end{array}$}} \\
\hline & & \multicolumn{2}{|c|}{$1 \mathrm{st}$} & \multicolumn{2}{|c|}{ 2nd } & & & & & & & & & \\
\hline & & $M$ & $S D$ & $M$ & $S D$ & $\mathrm{~L}_{4}$ & $\begin{array}{c}\text { Average } \\
S D\end{array}$ & Slope & $\mathrm{L}_{4}-\mathrm{D}_{20}$ & $\mathrm{D}_{0}-\mathrm{D}_{20}$ & $S D$ & $a$ & $b$ & $\tau$ \\
\hline W.L. & $\begin{array}{l}20^{\circ} \text { Topforward } \\
30^{\circ} \text { Topbackward }\end{array}$ & $\begin{array}{l}-3.2 \\
-3.2\end{array}$ & $\begin{array}{l}1.1 \\
1.2\end{array}$ & $\begin{array}{l}-3.3 \\
-4.2\end{array}$ & $\begin{array}{l}1.1 \\
1.2\end{array}$ & $\begin{array}{r}+7.8 \\
-17.9\end{array}$ & $\begin{array}{l}0.9 \\
1.3\end{array}$ & +0.51 & $\begin{array}{l}+12.3 \\
-14.0\end{array}$ & $\begin{array}{l}+7.8 \\
-5.8\end{array}$ & $\begin{array}{l}2.2 \\
1.7\end{array}$ & $\begin{array}{l}-4.6 \\
-4.0\end{array}$ & $\begin{array}{r}+10.1 \\
-6.3\end{array}$ & $\begin{array}{l}2.62 \\
4.47\end{array}$ \\
\hline C.Z. & $\begin{array}{l}20^{\circ} \text { Topforward } \\
30^{\circ} \text { Topbackward }\end{array}$ & $\begin{array}{l}-2.6 \\
-2.0\end{array}$ & $\begin{array}{l}0.4 \\
0.6\end{array}$ & $\begin{array}{l}-3.8 \\
-4.7\end{array}$ & $\begin{array}{l}0.6 \\
0.6\end{array}$ & $\begin{array}{r}+9.3 \\
-22.5\end{array}$ & $\begin{array}{l}1.2 \\
0.5\end{array}$ & +0.64 & & $\begin{array}{l}+5.3 \\
-9.7\end{array}$ & $\begin{array}{l}0.9 \\
1.2\end{array}$ & $\begin{array}{l}-3.3 \\
-4.7\end{array}$ & $\begin{array}{r}+6.5 \\
-11.1\end{array}$ & $\begin{array}{l}1.90 \\
5.83\end{array}$ \\
\hline L.M. & $\begin{array}{l}20^{\circ} \text { Topforward } \\
30^{\circ} \text { Topbackward }\end{array}$ & $\begin{array}{l}-1.0 \\
-3.4\end{array}$ & $\begin{array}{l}0.9 \\
1.1\end{array}$ & $\begin{array}{l}-1.3 \\
-2.5\end{array}$ & $\begin{array}{l}1.0 \\
1.2\end{array}$ & $\begin{array}{l}+14.7 \\
-19.0\end{array}$ & $\begin{array}{l}0.5 \\
0.8\end{array}$ & +0.67 & $\begin{array}{l}+15.4 \\
-15.3\end{array}$ & $\begin{array}{l}+6.7 \\
-8.9\end{array}$ & $\begin{array}{l}1.6 \\
2.1\end{array}$ & $\begin{array}{l}-0.2 \\
-3.7\end{array}$ & $\begin{array}{r}+7.9 \\
-10.5\end{array}$ & $\begin{array}{l}2.01 \\
2.81\end{array}$ \\
\hline W.H. & $\begin{array}{l}20^{\circ} \text { Topforward } \\
30^{\circ} \text { Topbackward }\end{array}$ & $\begin{array}{l}+4.5 \\
+3.3\end{array}$ & $\begin{array}{l}0.9 \\
0.3\end{array}$ & $\begin{array}{l}+5.0 \\
+2.6\end{array}$ & $\begin{array}{l}1.0 \\
0.6\end{array}$ & $\begin{array}{l}+13.5 \\
-16.9\end{array}$ & $\begin{array}{l}0.8 \\
0.5\end{array}$ & +0.61 & $\begin{array}{r}+7.2 \\
-17.0\end{array}$ & $\begin{array}{l}+6.0 \\
-6.3\end{array}$ & 2.9 & $\begin{array}{r}+7.2 \\
0.0\end{array}$ & $\begin{array}{l}+5.7 \\
-7.6\end{array}$ & $\begin{array}{l}3.81 \\
3.02\end{array}$ \\
\hline Average & $\begin{array}{l}20^{\circ} \text { Topforward } \\
30^{\circ} \text { Topbackward }\end{array}$ & $\begin{array}{l}-0.6 \\
-1.3 \\
\end{array}$ & $\begin{array}{l}0.8 \\
0.8\end{array}$ & $\begin{array}{l}-0.9 \\
-2.2\end{array}$ & $\begin{array}{l}0.9 \\
0.9\end{array}$ & $\begin{array}{l}+11.3 \\
-19.0\end{array}$ & $\begin{array}{l}0.9 \\
0.8\end{array}$ & +0.61 & $\begin{array}{l}+12.0 \\
-15.9\end{array}$ & $\begin{array}{r}+6.5 \\
-7.7\end{array}$ & $\begin{array}{l}1.6 \\
1.7\end{array}$ & $\begin{array}{l}-0.2 \\
-3.1\end{array}$ & $\begin{array}{l}+7.6 \\
-8.9\end{array}$ & $\begin{array}{l}2.59 \\
4.03\end{array}$ \\
\hline
\end{tabular}

Note-Measurements of VPEL in darkness at the beginning of the session against the erect dark pitchroom are displayed in the column headed "Predark 1st," measurements against the pitched dark pitchroom are in the column headed "Predark 2nd," and measurements against the twoline visual field are in the column headed "Light." Each VPEL value for a given condition is the mean for that condition across all of the different times. Positive and negative values of VPEL are settings above and below true eye level, respectively. The value of VPEL at each of the different times is displayed separately for each condition in Figure 6.

Each $S D$ value is the average standard deviation value across all of the times in the given condition; this average is taken of the individual standard deviations obtained separately at each time in the given condition; each of these individual standard deviations is the variation of the separate measurements among the individual trials at a given time in the given condition.

Values in the column headed "Slope" are the difference in Experiment 3 between the VPEL values of the two-line visual field in the same-eye condition divided by the difference in the two pitches $\left(50^{\circ}\right)$.

The column headed " $\mathrm{L}_{4}-\mathrm{D}_{20}$ " is the difference between the VPEL during the last minute of exposure to the two-line visual field and the VPEL values measured during the 20 th minute in darkness. " $D_{0}-D_{20}$ " is the range over which VPEL changed in darkness following extinction of twoline visual field from the first measurement in darkness to the last.

The curves representing the best-fitting values of the exponential decay function VPEL $=a+b e^{-t / \tau}$ during dark adaptation are displayed in Figure 6 . The units for all measured values and for best-fitting values for $a$ and $b$ are in degrees visual angle ( + and - indicate values above and below true eye level, respectively), units for $\tau$ are in minutes.

$\mathrm{D}_{20}$ (Table 1). As might be expected also, the average value of $b$ is $20 \%$ smaller following exposure to pitch at $20^{\circ}$ than pitch at $30^{\circ}$.

The fitted $b$ values for the two-line condition are also similar to the values for the $\mathrm{D}_{0}-\mathrm{D}_{20}$ ranges (Table 2). They are smaller than those for the corresponding sameeye full-field condition in Experiment 1, as might be expected from the smaller $D_{0}-D_{20}$ ranges.

The total change in the dark, $L_{4}-D_{20}$, averages $39 \%$ greater than the average value of $b$ in Experiment 1 (Table 1). This points us to a significant conclusion: If the initial precipitous drop from $\mathrm{L}_{4}$ to $\mathrm{D}_{0}$ was part of a unitary exponential decay, these two measures of the initial drop-the empirical $\mathrm{L}_{4}-\mathrm{D}_{20}$ measure and the theoretical value of $b$-should be equal. Clearly this is not so. A similar difference between the $\mathrm{L}_{4}-\mathrm{D}_{20}$ range and fitted values of $b$ holds for the two-line experiment, where the $L_{4}-D_{20}$ range averages $41 \%$ greater than the average value of $b$ (Table 2). This divergence between $\mathrm{L}_{4}-\mathrm{D}_{20}$ and $b$ must be looked on as a failure of Equation 2 to fully represent the complete dark adaptation process. Thus, the results of the fitting process indicate that the decaying exponential does govern a late process during dark adaptation, but not the early segment of the change of VPEL in darkness subsequent to extinguishing a pitched visual field.
One additional point that results from the fitting process is worth noting: Although the fitted value of $b$ for the cross-adaptation condition is smaller than the value of $b$ for the same-eye condition, the ratio of the average time constants for the two exponentials is +1.00 . This confirms the presence of a true scaling; the two exponentials do follow the same time course (i.e., are "parallel exponentials").

\section{DISCUSSION}

The discussion below will be centered on three matters: (1) relations between adaptation of VPEL measured in the present case and in other cases of adaptation of visual direction; (2) how adaptation of VPEL relates to the linear mechanism described earlier, in which the output of the visual system is combined with the output of the body-referenced mechanism; and (3) localization within the neural pathway at which adaptation of VPEL occurs.

\section{Discordance Between $V_{s}$ and $B_{s}$}

Egocentric visual localization in erect visual fields normally involves a concordance or near concordance between the egocentric visual directions specified by the normal orientation of the visual field and by the body- 
referenced mechanism. Disrupting the concordanceor producing discordance-has often been employed as a means of dissecting the processes controlling localization. In this context, "discordance" refers to situations in which two aspects of the stimulus can be assumed to signal two different values of the same perceptual dimension. It has also generally been assumed that a normal (i.e., usual) stimulus signals a veridical value of the perceptual dimension being measured, and that an abnormal (i.e., unusual) aspect of the stimulus signals a nonveridical value of the perceptual dimension. In the present experiments, the body-referenced mechanism would be expected to signal a veridical value of VPEL, and the pitched visual field would be expected to signal a value of VPEL that is mislocalized from true eye level; resolution of the discordance would then be carried out by a mechanism that finds a value intermediate between the two signaled values.

Discordances have been introduced in four main kinds of experimental situations (including the present one), and their introduction is normally followed by an adaptation to the discordance in which the correspondence of visual direction to physical location undergoes change with a measurable time course. The four kinds of discordance differ with regard to the locus at which they are introduced and in the manner by which they are produced. Two of these situations primarily involve the production of unusual orientations of the visual field relative to the observer: (1) direct manipulation of the visual field - for example, the present case with pitched visual fields, and (2) proximal stimulus changed by optics worn by the observer-for example, wedge prisms. The other two situations primarily involve unusual inputs from the body-referenced mechanism due to the introduction of changes in the relation between actual eye position and EEPI (curarized observer, externally produced ocular displacement). For the curarized observer, or for externally produced ocular displacement, the interesting conditions involve a normally oriented visual field along with a baseline value for the body-referenced mechanism that differs from that for the normal observer by virtue of disparities existing between EEPI and true eye position. For the cases involving pitched visual fields or prism adaptation, the baseline value for the bodyreferenced mechanism is normal and the discordance is produced by the abnormal orientation of the visual field.

\section{Same Mechanism for Curarized and Normal Observers}

Large spatial mislocalizations have been measured in subjects partially paralyzed by d-tubocurarine (Matin et al., 1982; Matin, Stevens, \& Picoult, 1983). The curare produces a reversible reduction in extraocular muscle efficiency marked by a severe reduction in the range of both horizontal and vertical eye movements. In normal room illumination, the reports of visual direction (VPEL and the horizontal location of visual targets set to appear straight ahead) by the curarized observer were essentially veridical. However, at the onset of darkness, a single, small, circular, foveated, visible target appeared to move in the direction in which the eye deviated from primary position (the paretic eye could be directed to points as far as $15^{\circ}$ from primary position) and appeared to remain localized at the position corresponding to the terminus of its motion as long as darkness was maintained. The full mislocalization typically took several minutes to develop, but was immediately corrected when room illumination was restored. The change of VPEL in darkness from immediately prior values in the light and the changes in light from immediately prior values in darkness each reached magnitudes that were similar to those measured in the present report with pitched visual fields and followed a similar time course.

However, the steady-state mislocalizations in darkness and near veridicality in full illumination manifested by the curarized observers are exactly the reverse of the steady-state effects we obtain with pitched visual fields in which we measure near veridicality in darkness and large mislocalizations in the presence of a pitched visual field. Nevertheless, it is clear that in both cases the transient adaptation during the first few minutes of darkness is the result of a transient reduction in the influence from $k_{v}\left(V_{s}+V_{o}\right)$, the weighted contribution from the visual field, as the aftereffects of the visual field dissipate with time following the onset of darkness. In both cases also, the rapid transition takes place following illumination onset, and in both cases the influence from the visual field directs VPEL toward the visual direction perpendicular to the visual field, whether it be erect or pitched (Equation 1).

\section{Two Recent Results Due to \\ Dark Adaptation of VPEL}

In experiments employing a smaller version of the pitchroom and a smaller range of pitch $\left( \pm 15^{\circ}\right)$, Stoper and Cohen (1989) obtained a linear relation between visual pitch and VPEL, as had Matin and Fox previously (1986, 1989). However, Stoper and Cohen (1989) also report two additional findings for which they consider instrumental artifacts as explanations.

1. They report a "downward drift" of VPEL in the dark over time (shown in their Figure 4):

Each block of 10 trials occupied approximately $10 \mathrm{~min}$. As our time sequence data show, there was considerable drift during these $10 \mathrm{~min} . .$. . The fact that eye level tended to drift down during the dark trials is something of a mystery, and we have no satisfactory explanation for this finding. (Stoper \& Cohen, 1989, p. 474)

This result is readily interpreted as a consequence of the fact that they employed the same sequence of pitches in all runs during illumination prior to the measurements in darkness (the sequence was $+15^{\circ}$ ("topforward"), $+7.5^{\circ}, 0^{\circ},-7.5^{\circ},-15^{\circ},-15^{\circ},-7.5^{\circ}, 0^{\circ},+7.5^{\circ},+15^{\circ}$ ). Since the last measurement during illumination was always with pitch set at $+15^{\circ}, 6$ VPEL was at its most ele- 
vated level immediately preceding the first measurement in darkness. Thus, the first VPEL measurements in darkness would be expected to yield the highest VPEL values and to be followed by lower values through the remainder of the dark period as dark adaptation progressed. This is exactly the result Stoper and Cohen (1989) report. The total extent of the variation and the form of the decrease in VPEL during the 10-min measurement period in darkness are similar to those in the present results (cf. their Figure 4 to our Figure 4). ${ }^{7}$

2. Stoper and Cohen (1989) also report a systematic influence of pitch on VPEL in total darkness, stating

The effect of orientation was very much smaller in the dark than in the light; it was nevertheless statistically significant. Somehow, even in what we had assumed to be complete darkness, information about pitchbox orientation must have been available to the subjects. One possible source of this information may have come from the laser target itself; as the subjects moved the laser past an inside edge of the pitchbox, the apparent path of movement was deflected. This deflection could have revealed to the subjects the location of the edge. (p. 473)

That result is readily interpreted as a consequence of the fact that the sequence of pitches in darkness began with $+15^{\circ}$ (topforward), descended to $-15^{\circ}$, and was then followed by a reversed ascending sequence (this was the same sequence of pitches that was followed in illumination). The initial descending order of pitch in darkness paralleled the descent of VPEL in darkness, and the subsequent ascending pitch sequence in darkness was obtained during a time when VPEL was changing more slowly (see Stoper \& Cohen, 1989, Figure 4). This sequence, which followed viewing of topforward pitch of $15^{\circ}$ as the final exposure during illumination, should lead to the appearance of the systematic increase of VPEL with increase of pitch in total darkness that Stoper and Cohen report.

Thus, no more is required for a satisfactory explanation of the two systematic characteristics of dark VPELs that Stoper and Cohen report than the variation due to dark adaptation in combination with their repeating measurement sequence.

\section{Same Mechanism for VPEL Adaptation and Externally Produced Ocular Displacement}

A properly placed push or pull on the eyelid produces a rotation of the eye that results in the appearance of movement and/or displacement of the visual field (Helmholtz, 1866/1963). Recently, Stark and Bridgeman (1983) carried out psychophysical measurements on a variation of the Helmholtz procedure. With the eye held in a stable displaced terminal orientation from finger pressure that was essentially constant (typically $5^{\circ}$ or so ocular displacement produced), measurements of the horizontal direction visually perceived as straight ahead (VPSA) do not deviate from values measured in normal illumination without external pressure on the lid, although when the procedure is carried out in darkness, deviations of VPSA approximate the magnitude of the ocular displacement (confirmed in a subsequent experimentBridgeman \& Fishman, 1985-although in a later experiment small influences on VPSA were measured in the presence of a visual field; Bridgeman \& Graziano, 1989). These results with externally produced ocular displacement are similar to those described above for the curarized observer for whom VPSA and VPEL are essentially unchanged by the curare in the presence of a structured visual field, but are in error in darkness when the direction of gaze deviates from a central position.

A significant main point of present interest in the results with externally produced ocular displacement is Stark and Bridgeman's (1983) report that when the field illumination was extinguished while the subject maintained pressure, a still-illuminated foveated target appeared to drift slowly in darkness toward the steadystate asymptotic position for a period of about $15 \mathrm{sec}$ from lightoff.

These observations receive a straightforward interpretation within the present context: The introduction of externally produced ocular displacement produces a discordance between eye position and EEPI, and it is this disparity that leads to a different value of $B_{o}$ for a given eye position than that without externally produced ocular displacement, and thus to a different dark value for the physical location of VPSA. Extinction of the visual field thus results in decay of the consequences of visual input to zero and return of VPSA to the pressure-influenced dark value that is offset from the value in the presence of the visual field in a manner similar to that for the curarized observer. Since the entire displacement of the eye produced by the external pressure is only about $5^{\circ}$ at most, it is not surprising that they report a briefer time course for return of the direction perceived as straight ahead relative to the time course we report above following the $15^{\circ}-20^{\circ}$ deviations of VPEL generated by viewing a visual field pitched at either $20^{\circ}$ or $30^{\circ} .8$

\section{Similarities Between Adaptation to Pitch and to Prismatic Displacement}

Relations between adaptation to visual pitch and to prismatic production of visual roll. Although the time course for decay of VPEL following extinction of the pitched visual field in the present experiments is similar to time courses measured for some forms of perceptual adaptation, the rise time following onset of the visual field is considerably shorter in the present case. For example, Redding $(1973,1975)$ reports that decay of adaptation following removal of prismatically generated optical roll, ${ }^{9}$ which induced changes in the orientation of a line that was perceived to be vertical (VPV), was exponential with time constants between 3 and $6 \mathrm{~min}$, but the buildup of adaptation during presentation of the distorted input was also exponential with a 6-to 7-min time constant-a value very different from the less-than-1- 
min value we report here. Interocular transfer of the adaptation was $82 \%$ in Redding's experiments with visual roll, similar to our value of $85 \%$ for VPEL. The similarity of the magnitudes of both the decay constants and interocular transfer between the present measurements of adaptation to visual pitch and Redding's measurements of adaptation to visual roll are striking and suggests the possibility of a connection between the mechanisms controlling the two.

Relations between adaptation to visual pitch and to prismatic production of lateral displacement. Wedge prisms provide a means of generating displacements of the optical input, whose main aspects are identical to rotations of the visual field around the eye of the observer. The essential aspects of the transforms generated by base-up and base-down prisms are optically identical to topbackward and topforward pitch, respectively (Matin et al., 1988), and generate influences on VPEL that are similar to those we have described for visual pitch (Matin et al., 1988; Rock, Goldberg, \& Mack, 1966).

Measurement of the time course of perceptual adaptation of VPEL following the introduction of a wedge prism has not yet been reported. However, several experiments measuring the time course of perceptual adaptation of VPSA to lateral displacement produced by baseleft and base-right prisms have been reported (Redding, 1973, 1975). These were carried out in parallel with their measurements of adaptation to optical roll described above, and yielded exponentially decaying adaptation to lateral displacement in darkness with time constants of 40-50 min as compared with the 3- to 6-min time constants for decay of adaptation to optical roll. Some of the difference in these decay durations may be a consequence of the fact that the observers engaged in considerable voluntary movement around their environment during the adaptation and that the adaptation to lateral displacement involves components of adaptation related to the movement.

\section{VPEL Adaptation and the Visual System}

Treating the VPEL discrimination in terms of discordance between signals from the visual system and the body-referenced mechanism allows us to treat some of the decisions regarding the locus of adaptation as questions about whether adaptation is stored in the visual system, the body-referenced mechanism, or at a point beyond which the two converge.

In an earlier report (Matin \& Fox, 1989), it was suggested that in a pitched visual field the weight given to the visual field by the mechanism controlling VPEL, $k_{v}$, was equal to the slope of the VPEL-versus-pitch function, whereas in darkness, $k_{v}$ was equal to 0 (Equation 1 ). Since weighting of the visual and body-referenced inputs would be expected to occur at a site of combination for the two influences, that interpretation treats the adaptation as specific to the mechanism controlling VPEL. It may be that this is so, and that what changes gradually during dark adaptation following exposure to a pitch whose influence has a magnitude $V_{s}$, is the value of $k_{v}$ from its value in illumination toward zero in darkness (the support for this has been somewhat less clear in subsequent measurements; Matin \& Li, 1994a). However, several aspects of the present results in combination with the results from other experiments point to the likelihood that the dark adaptation of VPEL is at least in part a consequence of the decline of residual activity in the visual nervous system at a stage prior to its convergence with signals from the body-referenced mechanism; if so, it may not be $k_{v}$ that changes, but signals from the visual system, $V_{s}+V_{o}$. The major pieces of evidence for this are listed below.

\section{Inference From Cross-Adaptation}

The effect measured with the nonadapted eye was only $85 \%$ of the influence with the adapted eye. If the adapted effect was solely in the body-referenced mechanism (i.e., beyond a convergence point for $V_{s}$ and $B_{s}$ ), the same-eye and cross-adaptation effects are more likely to be equal. The $15 \%$ that fails to transfer must be related to either the function of the visual system or the manner of its convergence with the body-referenced system. ${ }^{10}$

\section{Relations to Other Orientation-Specific Visual Adaptation}

The $85 \%$ cross-adaptation effect for VPEL is similar to cross-adaptation magnitudes in two sorts of visuospatial phenomena that are orientation-specific, as is the influence of the individual line on VPEL, but these two do not involve spatial norms and extraretinal involvement is extremely unlikely. These two phenomena are figural aftereffects (Ganz, 1966; Ganz \& Day, 1965; Gibson, 1933; Kohler, 1940; Kohler \& Wallach, 1944) and adaptation of contrast thresholds for gratings (Blakemore \& Campbell, 1969; Blakemore, Nachmias, \& Sutton, 1970). Ganz (1966) has convincingly shown that figural aftereffects involve changes at sites in the visual system that control light and dark adaptation; Bowen and Wilson (1994) have shown that a portion of the contrast threshold for sinusoidal gratings is an effect of luminance, making a retinogeniculate locus likely. The logic of Ganz's argument applies equally to the present case. A segment of this logic involves the time course of visual adaptation, whose relation to VPEL adaptation we summarize now.

\section{Similarity for Time Courses of VPEL and Rod Adaptation}

There is a strong resemblance between the quantitative features of the time course of light and dark adaptation of VPEL and of the rod threshold for detection of luminance measured with small spots of light. 1

1. The drop of VPEL within the first few seconds following the onset of darkness from its value in the preceding light period is precipitous. ${ }^{12}$ Thus, the total 
change of VPEL in the dark from the light-adapted value is $39 \%$ greater than the average value of the scaling parameter $b$ for the illuminated pitchroom and $41 \%$ greater for the two-line stimulus; in addition, the $y$ intercepts of the exponentials fitted to the measurements during dark adaptation are considerably below the VPEL values measured at the end of light adaptation. This result is mirrored in the adaptation of the rod intensity threshold by the fact that the logarithm of the rod absolute threshold following offset of a steady adapting background is characterized by an early precipitous drop from the level of the difference threshold against the adapting background, and is followed by a slower negatively accelerated decay to dark-adapted levels. The precipitousness of the rod threshold drop following exposure to intensities near those employed in the VPEL experiments with the illuminated background is indicated by the reduction of the rod threshold by $1.5 \log$ units within $1 \mathrm{sec}$ following extinction of a $2.4-\mathrm{mL} 4^{\circ}$ circular background centered $5^{\circ}$ from the fovea, as measured with a $200-\mathrm{msec}$ $0.5^{\circ}$ test flash centered on the adapted retinal region. Threshold during the subsequent $25 \mathrm{sec}$ decreases by only another $0.3 \log$ units, and proceeds to complete dark adaptation with only an additional $0.6-\log$-units decrease within the subsequent $40 \mathrm{~min}$ (Stewart, 1972). ${ }^{13}$ The difference threshold immediately before the onset of darkness is $1.22 \mathrm{log}$ units above the value that would best fall on the best-fitting exponential for the $200-\mathrm{msec}$ test flash and $0.81 \log$ units above that for a 5 -msec test flash (Stewart, 1972). Asymptotic recovery to darkadapted levels within 12 min following termination of exposure to light is typical of rod dark adaptation measured with detection sensitivity following exposure to intensity levels employed in the present experiments, similar to the decay of VPEL to its dark-adapted baseline.

2. Following complete dark adaptation, VPEL stabilizes quickly during exposure to a pitched visual field, and systematic changes beyond the first minute of exposure were not observed. This too mirrors the rapidity of light adaptation measured by the log intensity threshold. At the intensity levels employed in the present experiments, durations under 1-2 min for essentially complete light adaptation following complete dark adaptation are well within the range normally reported for intensity thresholds.

3. The 4-min average exponential decay of VPEL in darkness (Table 1) is within the range obtained with intensity thresholds, where 4 to $6.5 \mathrm{~min}$ are noteworthy figures for comparison, and values of as much as 12-20 min have also been reported (Pugh, 1975a, 1975b); compare to I.P. in Table 1 , where $\tau=19.6$ and $10.6 \mathrm{~min}$.

4. Although the luminance of the two-line pitchedfrom-vertical stimulus is about $1 / 350$ as great as the luminance of the illuminated pitchroom, and its retinal image contains only approximately $2 \times 10^{-6}$ as much light overall, its influence on VPEL during light adaptation is about four-fifths as large, and the time constant for decay of VPEL in darkness is reduced by a factor of less than 2. A quantitative disparity of this magnitude between visual stimulus and response points to an internal nonlinear compression similar to the one that has been invoked in treatments of adaptation of the intensity threshold for a long time. Thus, again, the response of the VPEL discrimination to intensity displays a marked resemblance to the logarithm of the detection threshold and suggests control at a common neural locus for at least some portion of the adaptation to them.

5 . The rod segment of variation of the logarithm of the intensity threshold with time in the dark has been reported to be well fitted by a decaying exponential function from all prior levels of light adaptation (Haig, 1941; Hecht, Haig, \& Chase 1937; Pugh 1975b). Since our particular interest here is in dark adaptation following light levels close to the ones employed in the present experiments, we fitted decaying exponentials to the lower four sets of Haig's (1941) data and to the decay following $0.1 \%, 0.5 \%, 2 \%$, and $7 \%$ rhodopsin bleaches measured by Rushton and Powell (1972), and again have obtained excellent fits. ${ }^{14}$ (The light levels in the present experiment with the illuminated background correspond to somewhat less than $0.1 \%$ bleached rhodopsin, as calculated by Rushton and Powell's approach.)

However, although the storage of rod adaptation is likely to be fairly complete at the retinogeniculate level, it is not clear that this would be so for the VPEL discrimination. Although we have no indication that the entire basis for the adaptation of VPEL that we report herein is a result of adaptation in the rods or in the retina, we also know of nothing that would place any portion beyond. In previous reports (Matin \& Li, 1992c, 1994b) we have presented reasons for believing that the VPEL discrimination is controlled in posterior parietal cortex. The present view that at least a portion of the VPEL adaptation consequent on exposure to a pitched visual field is stored in the retina readily conjoins with control in posterior parietal cortex, where joint influence from vision and the body-referenced mechanism are known to be involved.

\section{Adaptation of VPEL Within a Scotopic/Ambient System}

Reports of experiments with other aspects of egocentric localization and orientation have indicated major control by the peripheral visual field (Brandt, Dichgans, \& Koenig, 1973; Dichgans \& Brandt, 1974; Trevarthen, 1968), insensitivity to the accommodative stimulus (Leibowitz, Rodemer, \& Dichgans, 1979), at most a low level of sensitivity to change in stimulus intensity (Leibowitz et al., 1979), and control by large visual fields (Dichgans \& Brandt, 1974; Trevarthen, 1968). This has led to the suggestion (Leibowitz, Post, Brandt, \& Dichgans, 1982; Trevarthen, 1968) that visual processing of localization and orientation is under control of an "ambient" system, whereas the processing of fine detail and form is under control of a "focal" system, whose main control is by more central (i.e., foveal and near foveal) pro- 
cesses, involves perception of fine detail, and is sensitive to the accommodative stimulus. The original suggestions of the ambient/focal distinction proposed a separation of the processing of information related to spatial orientation and localization in superior colliculus from processing of visual form in cortex (Trevarthen, 1968; see also Held, 1968; Ingle, 1967; Schneider, 1967). Later work has led to suggestions of a separation of the processing of spatial orientation and localization from the processing of form, color, and motion by separate pathways leading out of striate cortex to posterior parietal cortex and inferotemporal cortex, respectively (Desimone, Schein, Morgan, \& Ungerleider, 1985; Matin \& Li, 1994b; Servos, Matin, \& Goodale, 1993; Ungerleider \& Mishkin, 1982).

The VPEL discrimination possesses the characteristics indicated above for the ambient system-dominance of large-field peripheral control, insensitivity to the accommodative stimulus, and minimal sensitivity at most to variation of intensity ${ }^{15}$ ( $\mathrm{Li} \&$ Matin, 1990; Matin \& Li, 1992b, 1992c, 1994b). Along with the fact that ambient functions are mainly mediated in the periphery, these characteristics also possess a marked overlap with the characteristics of scotopic vision, as has been noted previously (Trevarthen, 1968). However, in spite of the similarity of the time courses of VPEL adaptation and adaptation of rod-based detection sensitivity, as described in the previous section, and of the relative insensitivity of the scotopic system to refraction and intensity (e.g., slopes of the acuity-versus-luminance and flicker-versus-luminance functions are very much shallower for rods than for cones) and its major servicing by larger peripheral receptive fields, the identification of ambient and scotopic systems is less than certain (e.g., Leibowitz et al., 1979, find no effect of luminance beyond about $0.5 \log$ units above the absolute scotopic threshold for the latency and duration of circulovection). Nevertheless, although the similarity between the ambient/focal and scotopic/photopic distinctions may not be an identity, the extent of overlap is substantial and merits further attention.

\section{REFERENCES}

Blakemore, C., \& Campbell, F. W. (1969). On the existence of neurones in the human visual system selectively sensitive to the orientation and size of retinal images. Journal of Physiology, 203, 237260.

Blakemore, C., Nachmias, J., \& Sutton, P. (1970). The perceived spatial frequency shift: Evidence for frequency-selective neurones in the human brain. Journal of Physiology, 210, 727-759.

BowEN, R., \& WiLSON, H. R. (1994). A two-process analysis of pattern masking. Vision Research, 34, 645-657.

Brandt, T., Dichgans, J., \& Koenig, E. (1973). Differential effects of central versus peripheral vision on egocentric and exocentric motion perception. Experimental Brain Research, 16, 476-491.

BRIDGEMAN, B., \& FiSHMAN, R. (1985). Dissociation of corollary discharge from gaze direction does not induce a straight-ahead shift Perception \& Psychophysics, 37, 523-528.

Bridgeman, B., \& Graziano, J. (1989). Effect of context and efference copy on visual straight ahead. Vision Research, 29, 1729-1736.

Desimone, R. S., Schein, J., Morgan, J., \& Ungerleider, L. (1985).
Contour, color, and shape analysis beyond the striate cortex. Vision Research, 25, 441-452.

Dichgans, J., \& BRANDT, T. (1974). The psychophysics of visually induced perception of self-motion and tilt. In F. O. Schmidt \& F. G. Worden (Eds.), The neurosciences: Third study program (pp. $123-$ 129). Cambridge, MA: MIT Press.

GANZ, L. (1966). Is the figural aftereffect an aftereffect? A review of its intensity, onset, decay, and transfer characteristics. Psychological Bulletin, 66, 151-165.

GANZ, L., \& DAY, R. H. (1965). An analysis of the satiation-fatigue mechanism of figural after-effects. American Journal of Psychology, 78, 345-361.

GiBson, J. J. (1933). Adaptation, after-effect, and contrast in the perception of curved lines. Journal of Experimental Psychology, 16, $1-31$.

HAIG, C. (1941). The course of rod dark adaptation as influenced by the intensity and duration of pre-adaptation to light. Journal of General Physiology, 24, 735-751.

Hecht, S., Haig, C., \& Chase, A. M. (1937). The influence of light adaptation on subsequent dark adaptation of the eye. Journal of General Physiology, 20, 831-850.

HELD, R. (1968). Dissociation of visual functions by deprivation and rearrangement. Psychologische Forschung, 31, 338-348.

HeLmHOLTZ, H. L. F. voN (1963). Handbuch der physilogischen Optik [A treatise on physiological optics] (Vol. 3, J. P. C. Southall, Ed. and Trans.). New York: Dover. (Original work published 1866)

HOPPELER, P. (1913). Ueber den stellungsfactor der schrichtungen; eine experimentelle studie [An experimental study of eye level]. Zeitschrift für Psychologie, 66, 249-262.

INGLE, D. (1967). Two visual mechanisms underlying the behavior of fish. Psychologische Forschung, 31, 44-51.

KOHLER, W. (1940). Dynamics in psychology. New York: Liveright. KOHLER, W., \& WALLACH, H. (1944). Figural after-effects: An investigation of visual processes. Proceedings of the American Philosophical Society, 88, 306-315.

Leibowitz, H. W., Post, R. B., Brandt, T., \& Dichgans, J. (1982). Implications of recent developments in dynamic spatial orientation and visual resolution for vehicle guidance. In A. Wertheim, W. A Wagenaar, \& H. W. Leibowitz (Eds.), Tutorials on motion perception (pp. 231-260). New York: Plenum.

Leibowitz, H. W., Rodemer, C. S., \& Dichgans, J. (1979). The independence of dynamic spatial orientation from luminance and refractive error. Perception \& Psychophysics, 25, 75-79.

LI, W., \& Matin, L. (1990). Perceived eye level: Sensitivity to pitch of a vertical two-line stimulus grows with eccentricity but is biased by elevation. Investigative Ophthalmology \& Visual Science, 31 (3, Suppl.), 84.

LI, W., \& MATIN, L. (1991a). The influence of visual pitch on visually perceived eye level is spatiotopic. Bulletin of the Psychonomic Society, 29, 488. (Abstract)

LI, W., \& MATIN, L. (1991b). Spatial summation of influences on visually perceived eye level from a single variably pitched 1-line stimulus. Investigative Ophthalmology \& Visual Science, 32, 1272.

MacDougall, R. (1903). The subjective horizon. Psychological Review Monograph Supplement, 4 (1, Whole No. 17), 145-166.

Matin, L., \& Fox, C. R. (1986). Perceived eye level: Elevation jointly determined by visual field pitch, EEPI, and gravity. Investigative Ophthalmology \& Visual Science, 27 (3, Suppl.), 333.

Matin, L., \& Fox, C. R. (1989). Visually perceived eye level and perceived elevation of objects: Linearly additive influences from visual field pitch and from gravity. Vision Research, 29, 315-324.

Matin, L., Fox, C. R., \& Doktorsky, Y. (1987). How high is up? Investigative Ophthalmology \& Visual Science, 26 (3, Suppl.), 300.

MATIN, L., \& Li, W. (1989a). Linear summation of visual influences on perceived eye level. Journal of the Optical Society of America (Technical Digest Series, Annual Meeting), 18, 161.

Matin, L., \& Li, W. (1989b). A single pitched line in darkness controls elevation of visually perceived eye level. Investigative Ophthalmology \& Visual Science, 30 (3, Suppl.), 506.

MATIN, L., \& LI, W. (1990). Identical effects on perceived eye level by oblique lines in erect planes and pitched-from-vertical lines in 
pitched planes. Investigative Ophthalmology \& Visual Science, 31 (3, Suppl.), 328.

Matin, L., \& Li, W. (1991a). The Great Circle Model of spatial localization and visual perception of elevation. Society for Neuroscience Abstracts, 17 (Pt. 1), 848.

Matin, L., \& LI, W. (1991b). Separate mechanisms for perceived eye level and perceived vertical: Dissection by pitch and roll of a two-line stimulus. Investigative Ophthalmology \& Visual Science, 32, 900.

Matin, L., \& LI, W. (1991c). Visually perceived eye level, visually perceived vertical, and the Great Circle Model. Bulletin of the Psychonomic Society, 29, 526.

Matin, L., \& LI, W. (1992a). Light and dark adaptation of egocentric spatial localization. Investigative Ophthalmology \& Visual Science, 33, 959 .

Matin, L., \& LI, W. (1992b). Mislocalizations of visual elevation and visual vertical induced by visual pitch: The Great Circle Model. In B. Cohen, D. Tomko, \& F. Guedry (Eds.), Sensing and controlling motion: Vestibular and sensorimotor function (Annals of the New York Academy of Sciences, Vol. 656, pp. 242-265). New York: New York Academy of Sciences.

Matin, L., \& Li, W. (1992c). Visually perceived eye level: Changes induced by a pitched-from-vertical 2-line visual field. Journal of Experimental Psychology: Human Perception \& Performance, 18, 257-289.

Matin, L., \& Li, W. (1994a). The influence of the orientation of a stationary single line in darkness on the visual perception of eye level. Vision Research, 34, 311-330.

Matin, L., \& Ll, W. (1994b). Spatial summation among parallel lines across wide separation $\left(50^{\circ}\right)$ : Spatial localization and the great circle model. Vision Research, 34, 2577-2598.

Matin, L., \& LI, W. (in press). Mirror symmetry and parallelism: Two opposite rules for the identity transform in space perception and their unified treatment by the great circle model. Spatial Vision.

MATIN, L., LI, W., \& DokTORSKY, Y. (1988). Immediate prismatic correction: Its basis in monocular biconvergence perspective. Investigative Ophthalmology \& Visual Science, 29 (3, Suppl.), 409.

Matin, L., Picoult, E., Stevens, J. K., Edwards, M. W., JR., Young, D., \& MACARTHUR, R. (1982). Oculoparalytic illusion: Visual-field dependent mislocalizations by humans partially paralyzed with curare. Science, 216, 198-201

Matin, L., Stevens, J. K., \& Picoult, E. (1983). Perceptual consequences of experimental extraocular muscle paralysis. In A. Hein \& M. Jeannerod (Eds.), Spatially oriented behavior (pp. 243-262). New York: Springer.

Pugh, E. N. (1975a). Rhodopsin flash photolysis in man. Journal of Physiology, 248, 393-412.

PugH, E. N. (1975b). Rushton's paradox: Rod dark adaptation after flash photolysis. Journal of Physiology, 248, 413-431.

REDDing, G. M. (1973). Visual adaptation to tilt and displacement: Same or different processes? Perception \& Psychophysics, 14, 193-200.

ReDding, G. M. (1975). Decay of visual adaptation to tilt and displacement. Perception \& Psychophysics, 17, 203-208.

RoCk, I., GoldBERG, J., \& MACK, A. (1966). Immediate correction and adaptation based on viewing a prismatically displaced scene. Perception \& Psychophysics, 1, 351-354.

Rushton, W. A. H., \& Powell, D. S. (1972). The rhodopsin content and the visual threshold of human rods. Vision Research, 12, 1073 1081.

SCHNEIDER, G. E. (1967). Contrasting visuomotor functions of tectum and cortex in the golden hamster. Psychologische Forschung, 31, $52-62$.

Servos, P., Matin, L., \& Goodale, M. (1993). Visually perceived eye level in a visual form agnosic. Investigative Ophthalmology \& Visual Science, 34, 1416.

ShaRP, W. L. (1934). An experimental study concerning visual localization in the horizontal plane. Journal of Experimental Psychology, 17, 787-797.

Stark, L., \& Bridgeman, B. (1983). Role of corollary discharge in space constancy. Perception \& Psychophysics, 34, 371-380.

STEWART, B. (1972). Temporal summation during dark adaptation. Journal of the Optical Society of America, 62, 449-457.
Stoper, A. E., \& COHEN, M. M. (1986). Judgments of eye level in light and in darkness. Perception \& Psychophysics, 40, 311-316.

STOPER, A. E., \& COHEN, M. M. (1989). Effect of structured visual environments on apparent eye level. Perception \& Psychophysics, 46, 469-475.

TREVARTHEN, C. B. (1968). Two mechanisms of vision in primates. Psychologische Forschung, 31, 299-337.

UNGERLEIDER, L. G., \& Mishkin, M. (1982). Two cortical visual systems. In D. J. Ingle, M. A. Goodale, \& R. J. W. Mansfield (Eds.), The analysis of visual behavior (pp. 549-586). Cambridge, MA: MIT Press.

\section{NOTES}

1. "Pitch" or "visual pitch" refers to a rotation of the visual field around any horizontal axis within a frontoparallel plane of the observer.

2. Subject I.P. was one of the first 2 subjects for whom systematic measurements were taken following the initial pilot work for the experiment. After his first session, we took the precaution of blindfolding the subjects (including goggles) during the operation of pitching the room between the initial measurements in darkness against the erect room and against the pitched room, instead of merely requesting that they close their eyes. Although each pitch condition with all of the other 5 subjects and the condition for I.P. with the room pitched topforward involved only four cycles of light and dark measurements, the results displayed for I.P. with the room pitched topbackward involve eight cycles taken over three sessions; the results in the latter two sessions were much closer to agreement with those of the other subjects, although the deviation was still present.

3. Subject G.V.'s slope of +0.14 is the lowest that we have measured with the full pitchroom. The magnitude of the deviation of VPEL and the subsequent dark adaptation function, although clearly in the same direction as those of the other subjects, are too small to be reliably fitted by Equation 2. Although fits were obtained for G.V.'s data, and the resulting curves are displayed in Figures 4 and 5, they were not sharp; the values actually fitted to the results were similar to those of the other subjects, but were excluded from Table 1

4. No improvement is gained by fitting the results to a hyperbola. Although the three parameters of Equation 2 can be treated as independent, the appearance of a smaller scale factor in Equation 2 than is necessary to account for the values of $\mathrm{L}_{4}-\mathrm{D}_{20}$ could be modified by a shift of the zero on the time axis by $t_{o}^{\prime}$ in Equation 2 and writing

$$
\operatorname{VPEL}(\theta, t)=a+b^{\prime}(\theta) e^{-t^{\prime} / \tau},
$$

where $b^{\prime}=b e^{t^{\prime} o / \tau}$ and $t^{\prime}=t+t_{o}^{\prime}$. In this equation, any change of $b$ to $b^{\prime}$ is entirely compensated by resetting $t$ to $t^{\prime}$. If $t_{o}^{\prime}$ is allowed to vary for best fit, equally good fits are obtained for which $b^{\prime}$ equals $L_{4}-D_{20}$ in each case. No single value of $t_{o}^{\prime}$ works for all cases, however; values of $t_{0}^{\prime}$ required for best fit extend over a range of as much as $4 \mathrm{~min}$.

5. A typical consequence of a variable displacement among individual dark adaptation trials on a VPEL-versus-time graph is to stretch decay of the average result considerably relative to any individual trial; this leads to the generation of a longer calculated decay constant when Equation 2 is fitted to the average result than would hold for the typical single cycle. For example, for I.P.'s topbackward measurements, the decay constant for the best-fitting exponential to the average VPEL values across the four cycles was $19.6 \mathrm{~min}$, compared with $12.7 \mathrm{~min}$ for the average of the four decay constants from the separate fits to the four cycles. The cycle-to-cycle variability in these measurements for I.P. was the largest for any set of measurements for any subject $(S D=$ $5.0^{\circ}$ ). However, similar effects of averaging on the decay constant exist in a number of the results, such as topforward dark adaptation data for I.P. (3.6 vs. 2.3$)$, G.V. (5.21 vs. 3.2$)$, L.M. (6.9 vs. 3.3$)$, and W.L. (3.9 vs. 3.1). Values of $b$ are similarly susceptible to displacements among individual dark trials; values of $a$ are much less so.

6. Stoper and Cohen (1989) indicate a different order of pitches (see the bottom of their p. 472). However, their statement and its reference to their Figure 4 makes it clear that the sequence they employed is the 
one we indicate above, which terminated with $15^{\circ}$ topforward; we have communicated this to Stoper and Cohen and they have agreed.

7. Stoper and Cohen (1989) apparently attempted to avoid some problems akin to dark adaptation, describing the temporal characteristics of their measurement sequence in their procedure section as follows: "A block of 10 trials was presented in the dark, followed by another block in the light, followed by at least a 5-min break, then dark and light again. The sequence was used to minimize the influence of a light condition on a following dark condition" (p. 472). However, the 5-min break was apparently not sufficient to avoid the dark transient. Additional support for the present interpretation of Stoper and Cohen's result as due to changes during dark adaptation is the fact that the transient change in VPEL in darkness at the beginning of their session is smaller than the one later in the session. Since the dark measurements early in the session followed exposure to the erect external visual environment, VPEL would be expected to deviate less from the dark baseline than VPELs later in the session following exposure to the visual field pitched $15^{\circ}$ topforward, as they report.

8 . It is worth noting that for the curarized observers in the experiments of Matin et al. (1982) with downward direction of gaze, the downward drifts occurred quite regularly following extinction of the room illumination. Although horizontal drifts did occur with extinction of room illumination in the presence of horizontal ocular deviations from primary position, these were sporadic and could not be counted on to appear.

9. Although the term tilt is commonly employed for rotation around an axis from the eye of the observer to the frontoparallel plane, it has also been employed to represent other rotations as well. We prefer the term optical roll, whose meaning should be unmistakable as referring to a rotation around the axis of the eye of the observer in a plane perpendicular to the frontoparallel plane.

10. A portion of the difference between the same-eye and crossadaptation effect could also be due to a difference in the way in which the contralateral and homolateral visual fields influence the value of $B_{s}$ involved in the monocular VPEL discrimination. A portion of the $85 \%$ of the VPEL discrimination that does transfer is likely to be a consequence of changes in activity in the body-referenced system, but it also remains possible that a portion results from changes in the visual system, $V_{s}$.

11. Since the two-line stimulus in the present experiments was both $\operatorname{dim}(0.01 \mathrm{~mL})$ and viewed with peripheral retina $\left(25^{\circ}\right.$ horizontal eccentricity), the main stimulation was to the rod system. Although the lines' luminance was $0.5-1.0 \mathrm{log}$ units above the cone threshold, the sparseness of the cone distribution at $25^{\circ}$ eccentricity makes it unlikely that the cones were involved. (On the other hand, the laser target set to
VPEL was foveally viewed, indicating an interaction across a $25^{\circ}$ span.)

12. Our present technology did not allow us to efficiently measure the change of VPEL within seconds of the extinction of illumination in the pitched visual field. Trial-to-trial variation in the number of changes of elevation of the target before a VPEL null was approved by the subject involved a time window around each measurement, which extends as much as $30 \mathrm{sec}$ beyond the times indicated on the abscissae of Figures 4 and 5.

13. The decrease during the first second following extinction of the background involved a shift of the measurement to absolute threshold from the difference threshold. The final difference threshold measurement was made $6 \mathrm{sec}$ before background extinction, and the first absolute threshold measurement in darkness was taken 1 sec after background extinction in order to avoid the transient changes associated with background luminance steps at background offset. There are very few data sets that contain measurements of difference thresholds prior to termination of light adaptation along with absolute thresholds early in dark adaptation for which the momentary transients surrounding the introduction of a step to the adapting background do not become confounding issues; Stewart's (1972) is one of these few.

14. Haig (1941) drew decaying exponentials through his results (see his note 3, p. 745) but did not indicate goodness of fit, although visual inspection suggests that the fit was excellent; our fit to his numerical results confirms the excellence of the fit. Although Rushton and Powell (1972) display large departures between their measurements of thresholds during dark adaptation following weak bleaches and the decaying exponential that they predict from rhodopsin regeneration, we obtain excellent fits of a decaying exponential to Rushton and Powell's data when the restriction from measurements of rhodopsin regeneration is removed.

15. The comparison of illuminated pitchroom and two-line stimulus is not based on the luminance variable in isolation. Thus, it is possible that some of the other differences between the two conditions (e.g., sidewalls, many small lines in the pitchroom, etc.) are responsible. However, both stimuli (pitchroom and two-line) produce nearsaturating effects on the slope of the VPEL-versus-pitch function (see Matin \& Li, 1992b, 1994b), and so adaptation to each would have been near maximum at lightoff. The difference between the lack of influence of luminance on circulovection and the small influence of luminance on VPEL may be related to a difference in processing moving and stationary stimuli.

(Manuscript received October 22, 1993; revision accepted for publication July 13, 1994.) 